FSM IIImî Araştırmalar Insan ve Toplum Bilimleri Dergisi

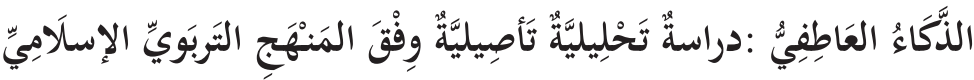 (İmad Kenan)* عماد كنعان
}

ملخص الدراسة باللغة العربية

هدفت الدراسة إلى تحليل مبدأ الذَّكَاءٍ العَاطِفِيٍ الفرديّ والجماعيِّ وتأصيله في ضوء المنهج التربوي في السنة النبوية. وقد استخدم الباحث المنهج الوصفي التحليلي والمنهج التوثيقي التأصيلي عبر أداتي الاستقراء والاستنتاج للتعرف إلى

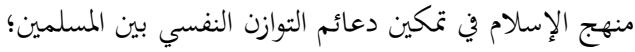

وذلك بالاعتماد على منهج بحثي يقوم على التوثيق للأدلة الشرعية، ثخم تحليلها لتحديد سبل بناء منظومة الذَّكَاءِ العَاطِفِيِّ الفردي والجماعي في مختلف مفاصل المختمع المسلم.

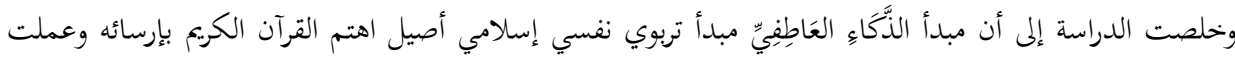

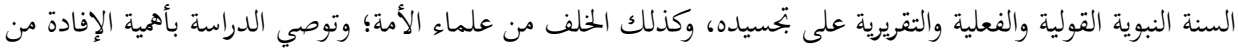

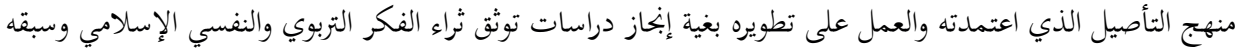
في إرساء مبادئ الصحة النفسية عبر إظهار تعدد أساليب الشريعة الخاتمة وتنوع غاياتما. الكلمات المفتاحية :الذَّكَاءُ العَاطِفِيُّ, المنهج التربويُّ الإسلاميّ, الذَّكَاءُ العَاطِفِيٌٌ الفرديُّ والجماعيُّ

$$
\text { (الباحث الدكتور، جامعة كيليس كلية الإلهيات ، كيليس/ التركية }
$$

Yrd. Doç. Dr., Kilis 7 Aralık Üniversitesi İlahiyat Fakültesi, Kilis/Türkiye, dr.emadkanaan@gmail. com 


\section{Duygusal Zekâ : İslami Eğitim Metoduna Uygun Analitik Bir Çalışma}

\section{Öz}

Bu çalışma; Hz. Peygamber'in sünnetinin eğitim yöntemi ışığında, ferdî ve toplumsal olarak duygusal zekâ ilkesi ve kökeninin incelenmesini hedeflemektedir.

Araştırmacı Müslümanlar arasında psikolojik denge dayanaklarının oluşumunda İslami yöntemin tanıtımında, tümevarım ve tümdengelim yöntemleri aracılığıyla betimsel analitik metodu ve dokümanter metodu kullanmıştır. Şer-i delillerin belgelendirilmesini temel alan araştırma yöntemine dayanarak İslam toplumunun çeşitli katmanlardaki birey ve toplumun duygusal zekâ sisteminin yapılanması yollarının belirlenmesini analiz etmektedir.

Araştırma duygusal zekâ ilkesinin, Kuranı kerimin yerleştirilmesini önemsediği, sözlü, fiili ve takriri nebevi sünnetin ve ümmetin halef âlimlerinin somutlaştırılmasına çalıştığ1, özgün bir İslami psikolojik eğitim ilkesi olduğu sonucuna varmıştır. Çalışma, dayand1ğ1 dokümanter yöntemin yararının önemli olduğunu, bununla birlikte son din İslam'ın çok yöntemli ve çok amaçlı yönünü göstererek, İslami pedagojik ve psikolojik düşüncenin zenginliğini ve psikolojik sağlık ilkelerinin yerleştirilmesinde ilk olduğunu ortaya koyan çalışmalar yapmak amacıyla bu yöntemin geliştirilmesini tavsiye etmektedir.

Anahtar Kelimeler: Duygusal zekâ, İslami eğitim metodu, bireysel ve toplumsal olarak duygusal zekâ.

\section{Emotional Intelligence: An Analytical Study in Line with Islamic Education Method}

\section{Abstract}

The study aims at consolidate identity Of Kant's educational philosophy under the educational Islamic point of view. The investigator does his study through the descriptive analytic method using inference and induction tools to identity The most important educational values the principles and learning methods that kant,s educational philosophy called for it.

After that he starts the comparison With educational learning theory through the educational Islamic point of view that is based on documenting then analyzing the legal evidences to identify the learning principles adopted by it and to show the educational values emerging from it and to define points of contrast and differentiation between Kant's educational philosophy thought and the modern Islamic education thought.

The study concludes that There are several contrasting points and meeting points between Kant's educational philosophy and the philosophy of Islamic educational.. And it says to benefit from the method of consolidation that it uses and to work to improve it aiming at achieving studies that proves that the Islamic educational thought has been precursor in establishing principles and methodologies in teaching that have various methods and numerous aims.

Keywords: Emotionality intelligence, Islamic educational curriculum, emotional intelligence at individual and societal levels. 


\section{أولاً: خطة البحث}

$$
\begin{aligned}
& \text { - } \\
& \text { 2- مشكلة البحث: } \\
& \text { 3- - أهمية البحث ومسوغاته: } \\
& \text { 4- أهداف البحث: } \\
& \text { 5- مصطلحات البحث: } \\
& \text { 6- الدراسات السابقة }
\end{aligned}
$$

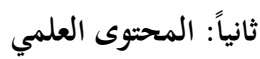

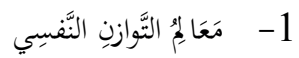

2- تحقيق معايير الذكاء العاطفي في السيرة النبوية (إمام الأَذكِيَاءٍ عاطفيَّاً) 3- توظيف منظومة الذكاء العاطفي في المراحل الدقيقة (النِّفَاق.. وِّكُر الخديعةِ وخندق أرباجها)

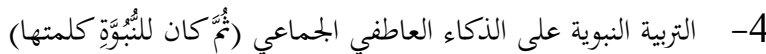
5- تحين الجماعة من التفرق في ظلال مبادئ الذكاء العاطفي الراسخة (الشَّاردِ والقِنْدِيل) 6- التوازن العاطفي لدى الصحابة الكرام (قَبَسٌُ من أنوار الشَّيخين) 7- التوازن العاطفي لدى الصحابة الكرام (فقه الحُبِّ القويم) 8- التوازن العاطفي لدى الصحابة الكرام (بصيرة الوَلَدِ والأُمِّ ) 9- التوازن العاطفي لدى التابعين الكرام عَابِدَةُ الإسلام الأولى 10- التوازن العاطفي لدى التابعين الكرام (حَمَّاد... نموذج العَا لِّهُ العَامِلُ) 11 - الذَّكاءُ العَاطِفِيٌُ الجماعيُّ

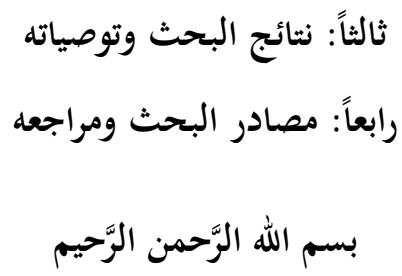




\section{أولاً: خطة البحث}

1- اليُقَقَّمة:

ولد مصطلح الذكاء العاطفي في الولايات المتحدة الأمريكية قبل عشرين عاماً، إذ لاحظ علماء النفس

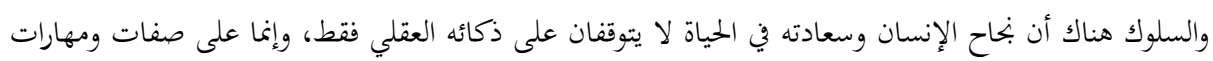

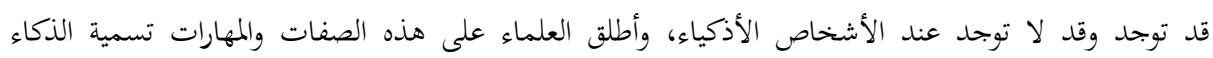

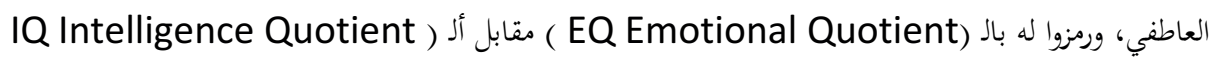

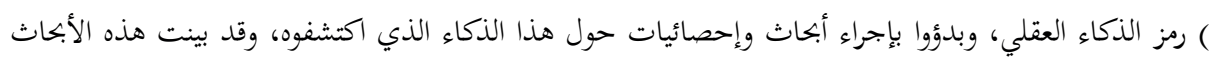

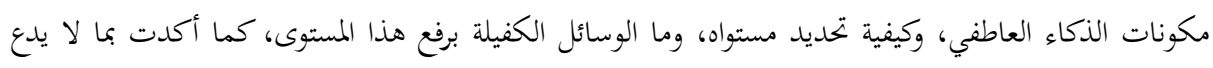
بحالاً للشك أن النجاح والسعادة في الحياة متوقفان على مستوى الذكاء العاطفي عند الإنسان، وليس على مستوى

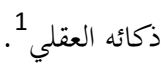

ويعدُّ الذَّكَاءُ العاطفيٌُ أحد أنواع الذكاءات المتعدّدة الموجودة لدى الإنسان، والذي حدّده علماء كثر في منتصف

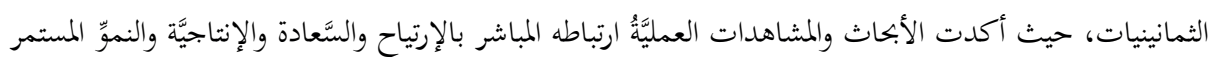
للشخص على الصعيد الأسري، والمهني والاجتماعي.

ويعرَّفُ النَّكَاءُ العاطفيُّ على أنه: القدرة على فرز عواطف الإنسان وأحاسيسه، وحسن استعماها، ويعرف

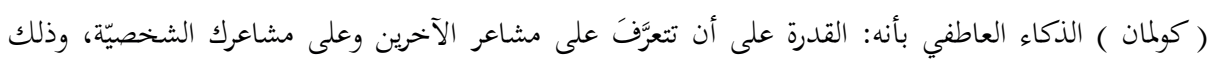
لتحفيز أنفسنا، ولإدارة عواطفنا بشكل سليم وجيّد في علاقتنا مع الآخرين.

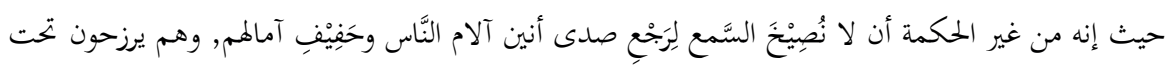

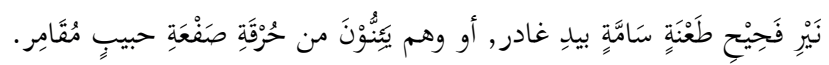

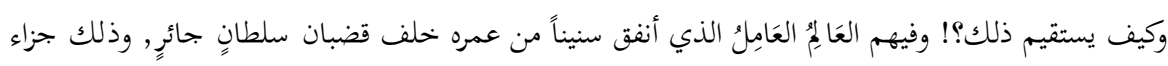

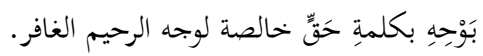

(1 ) - ياسر تيسير العيتي: (الذكاء العاطفي، نظرة جديدة في العلاقة بين الذكاء والعاطفة)، (5) ( ) - دانييل جولمان: (الذكاء العاطفي)، (52). 


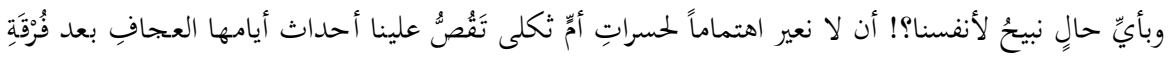

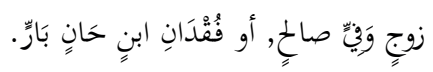

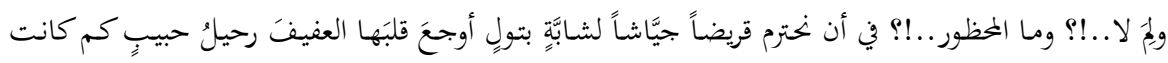

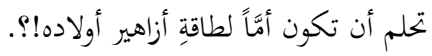

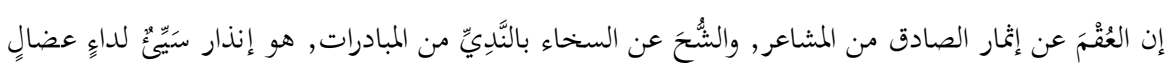

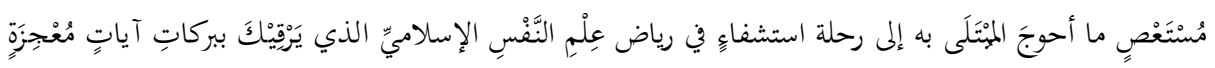

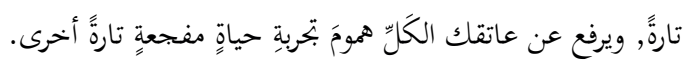

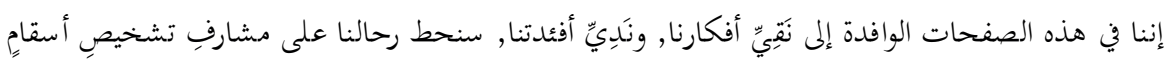

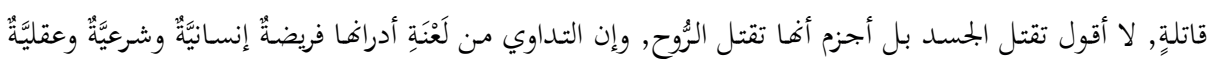

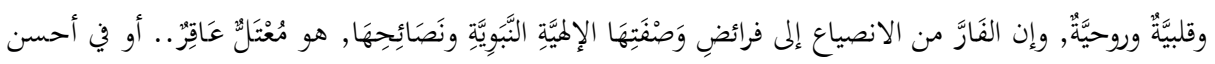
أحواله مهووسُ عَاقُّ.

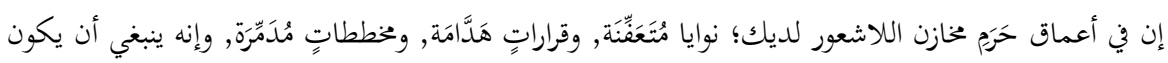

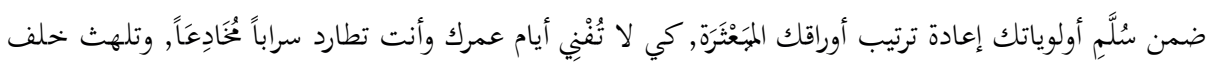

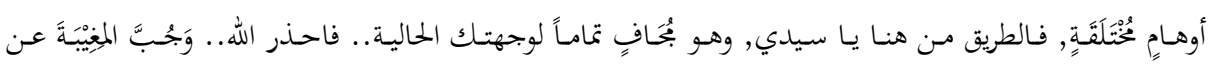

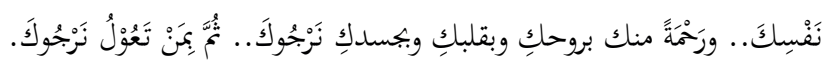

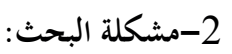
إنّ من أسرار السعادة أن يكتشف الإنسان نفسه، وأجمل شيء في هذه الحياة أن يعرف الإنسان قيمتهُ

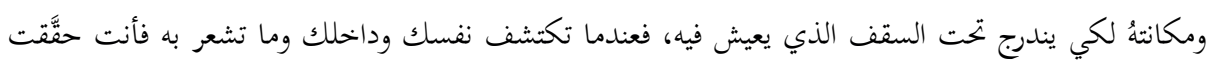
نصف متطلبات النجاح في التعامل مع الناس، فالإنسان عندما يعرف قيمته بين الناس تنتج عنه تصرّفات تطابق

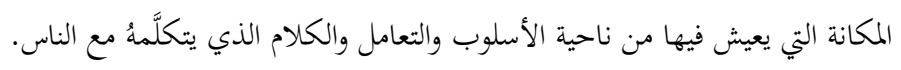

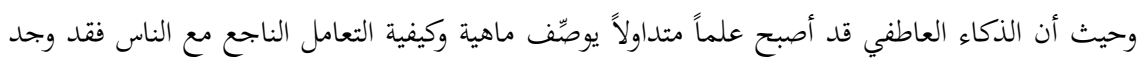
الباحث أنه من الخير أن يقدم توصيفاً تحليلياً تأصيلياً يبين فيه رؤية الفكر التربوي الإسلامي لمبدأ النَّكَاءُ العاطفيُّ.

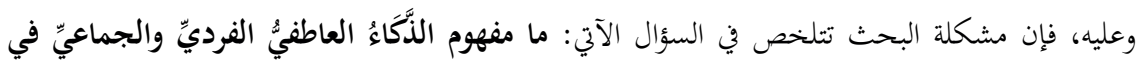


3-أهمية البحث ومسوغاته: تتلخص أهمية البحث ودوافع كتابته في النقاط الآتية:

أ- - التعريف بمفهوم الذَّكَاٍِ العاطفيّ الفرديّ والجماعيّ في المنظور التربوي المعاصر. ب- - تقديم الرؤية الإسلامية لمفهوم الذَّكاءٍ العاطفيِّ. ت- - تسجيل قَصَبِ السَّبْقِ للشريعة الإسلامية في تخريج أجيال متتالية من المسلمين تحلت بأعلى منازل الذَّكَاءٍ العاطفيِّ وخصائصه.

ث- - التعريف بالنَّكاءِ العَاطِفِيٍ الجماعيّ بوصفه أحد حاجات الأمة الملحة الحالية لإبحاز التغير المنشود والعودة للماضي البحيد.

4-أهداف البحث: يَنْشُدُ البحث تحقيق الأهداف الآتية:

أ- التعريف بمفهوم الذَّكَاءٍ العاطفيّ الفرديّ والجماعيّ في المنظورين التربوي المعاصر والإسلاميّ أيضاً. ب- - تبيان شمولية الشريعة الإسلامية ومحاكاتما لعديد العلوم النفسية والتربوية الحديثة النافعة. 5- 5 مصطلحات البحث: ومن أهمها الآتي:

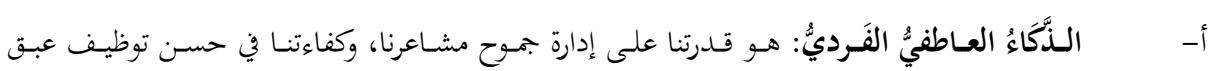
أحاسيسنا.

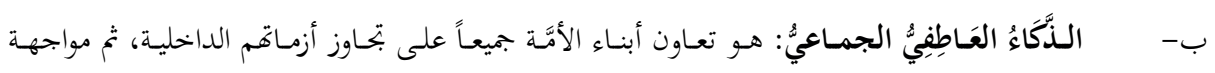
مشكلاتقم الوافدة.

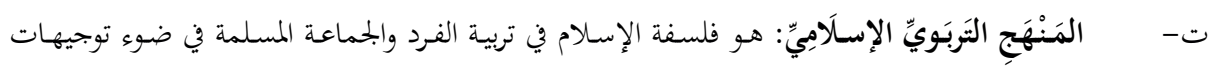
الكتاب والسُّنَّة.

7- الدراسات السابقة: من أهم الدراسات السابقة ذات الصلة التي وقع عليها الباحث ما يأتي: أ- ما فوق الذكاء العاطفي.. حلاوة الإيمان

$$
\text { تاريخ النشر: الباحث: د. ياسر العيتي }
$$

ملخص البحث: يتناول هذا البحث ولادة مصطلح جديد علمي باسم الذكاء العاطفي، أي قدرة الإنسان على التعامل الإيجابي مع ذاته ومع الآخرين، ليحقق أكبر قدر من السعادة لنفسه ولمن حوله، ويوضح عناصر كل من الذكاءين العقلي والعاطفي. ويبين تنمية الإسلام عند الصحابة والتابعين مهارات الذكاء العاطفي، وكيف يشعر 
الإنسان بحلاوة الإيمان عند تحليه بتلك المهارات ويربطها بربه ودينه وآخرته. ولماذا لم يعد الإسلام مؤثراً في معظم المسلمين اليوم، ولماذا اختار الله تعالى العرب من بين الأمم للنهوض برسالة الإسلام. ويوضح الكتاب عندما تكون الحياة الله، كيف يدرك الإنسان ذاته وغايته في الوجود ومبادئه وقيمه، ويصف أحباء الله. ويشرح كيف يتحكم الإنسان بالمشاعر السلبية كالخوف والقلق والغضب، وكيف يتخلص منها، ويتجاوز المحن والأزمات، وتصبح النفس مطمئنة بالإسلام. ويصف الكتاب الصدّيقين، وكيف أعلى الله درجاهم. ويتكلم عن القادة اللينين واتصاف قيادهم الحقيقية باحترام الإنسان ومحاورته وإقناعه، ويدعو إلى عدم التفرق وقبول الاختلاف البّناء، وعدم إلغاء الآخر، وتحمل المسلم مسؤولياته بإيمانه وحركته ومبادرته وإيجابيته واقتحامه الظروف، ويصف الكتاب حياة المسلم المؤمن المتمتع بالذكاء العاطفي، وكيف يعيش لله حياة متوهجة بالحب والعزم والأمل، مليئة بالمشاعر.

$$
\begin{aligned}
& \text { ب- الذكاء العاطفي الذاتي وتطبيقاته في السنة النبوية } \\
& \text { الكاتب: علي إبراهيم سعود عجين } \\
& \text { تاريخ النشر:2009م }
\end{aligned}
$$

ملخص البحث: يتناول هذا البحث موضوع الذكاء العاطفي وهو: قدرة الإنسان على التعامل الإيجابي مع ذاته ومع الآخرين، لتحقيق أكبر قدر من السعادة لنفسه ومن حوله. حيث وجد الباحث أن السنة النبوية حافلة بتطبيقاته العلمية في جميع بحالاته وهي: معرفةالإنسان لانفعالاته والوعي بالذات. وإدارة العواطف والتحكم .ها. وتحفيز النفس لتحقيق الأهداف الذاتية. ومعرفة عواطف الآخرين والتقمص الوجداني. والمهارات الاجتماعية. وتم التركيز على المحالات الثلاثة الأولى وهو ما يعرف بالذكاء العاطفي الذاتي. وبين الباحث تميز الذكاء العاطفي المستنبط من السنة النبوية لأنه مرتبط بالإيمان بالله تعالى، وأثر ذلك في تحقيق تأجيل الإشباع ، والصبر، والتفاؤل، وتوجيه النفس نحو تحقيق العبودية لله تعالى. كما أوصى الباحث الدارسين للسنة النبوية بتوجيه اهتماماتم نخو بيان أثر السنة النبوية في علم النفس بشكل عام والذكاء العاطفي بوجه خاص. 


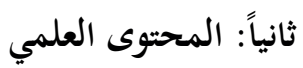

سوف يعابج البحث من خلال هذا الفصل الملامح الرئيسة التي توثق تحلي أبناء الأمة المسلمة بأعلى المي

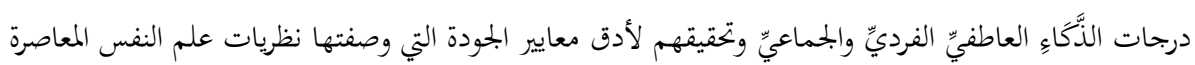

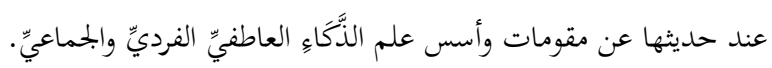

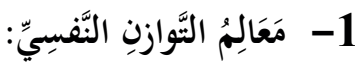

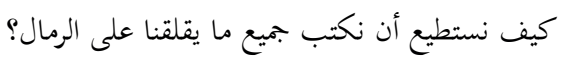

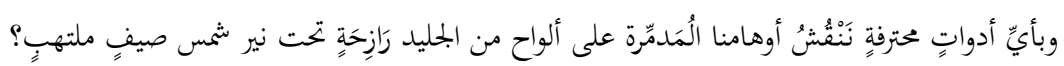

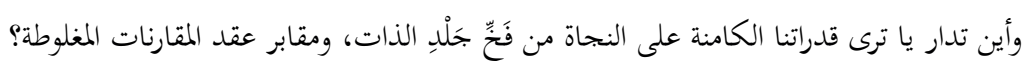

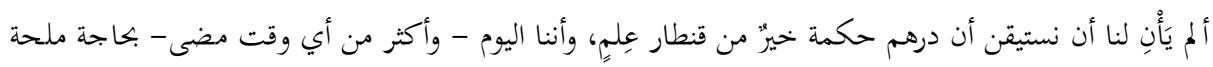

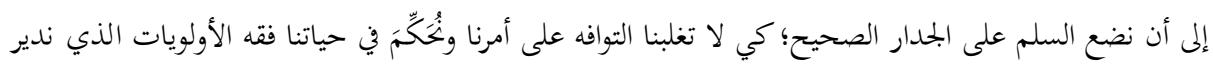

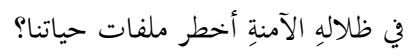

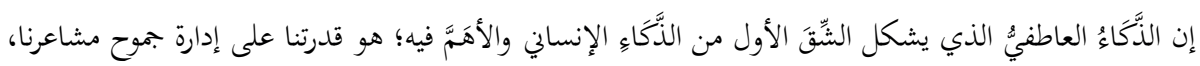

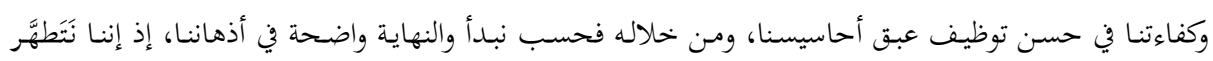

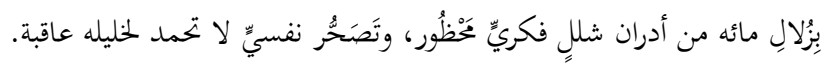

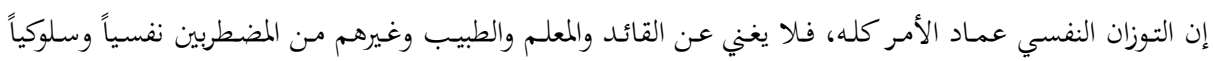

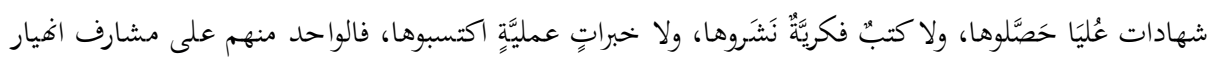

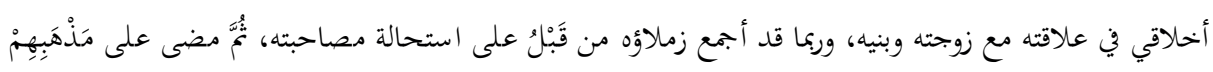

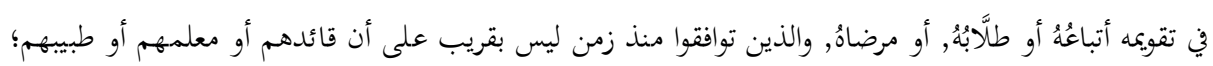

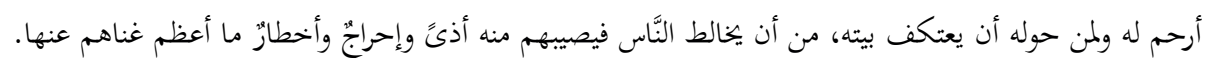

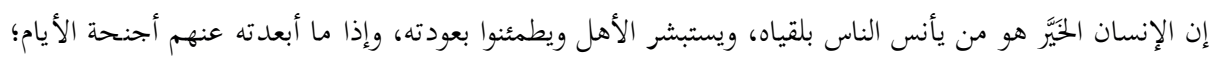

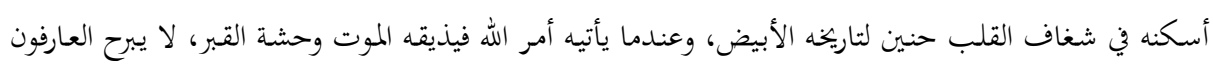

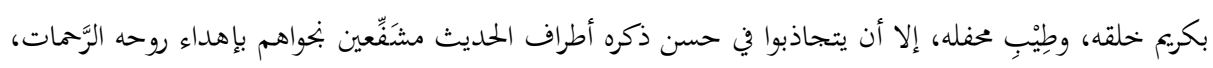




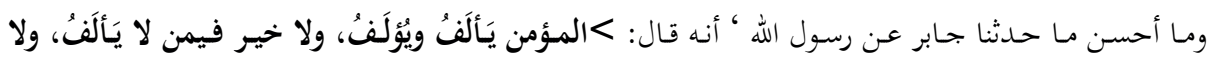
يُؤَلفُ، وخير النَّاس أنفعهم للنَّاس >(1). إن العلم والثراء والسلطان والجحاه والجمال، والذوق الرفيع في الملبس والمأكل والمسكن، عوارض عابرة لا تترك عند الناس من دون منظومة أخلاقية راسخة في قلب الإنسان، ومتَّقدة في قوله وعمله إلا أثراً عكسياً سلبياً، فتنقلب

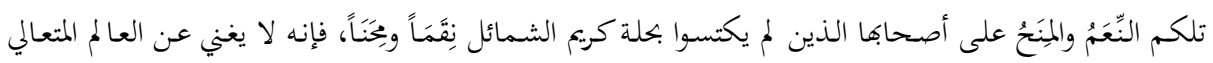
جزالة وعظه، ولا عن الغني المحتال كثرة ماله، ولا عن السلطان الجائر قوة كرسيه، ولا عن الجميل طلائع حسنه، وإن

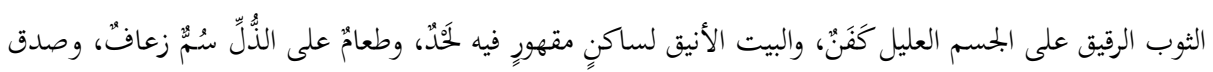

رسول الله ' إذ قال: >إنكمم لن تَسَعُوا الناس بأموالكم، فَلَيَسَعْهُم منكم بَسنطُ الوجه، وحُحْنُ الخُلُقِ >(2). إن الذَّكَاءَ العاطفيَّ يتجلَّى في مظاهر عديدة من الاتزان في المشاعر، وقوة المحافظة على المبادئ، والثبات على المثُّلِ التي يعتقد المرء بصحتها، وهو كفاءة عالية لا يمتلكها إلا عينة قليلة من النَّاس؛ تتجلَّى عندهم في حسن قيادة قلوب

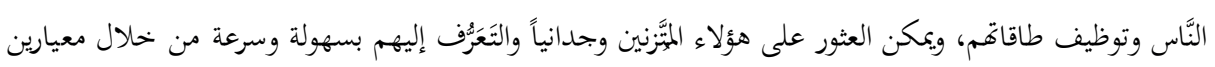
دقيقين للغاية:

الأول منهما: قدرقم على محاكاة هموم الناس وحاجاقهم، والتفاعل معها على نحو بَنَّاء، والثاني يتمثل في قوة ثباتم على مستوى التواصل الإيجابي مع الناس وديمومته، بحيـث يَنْلُصون مـن جهدهم النوعي هذا إلى كسبب وِدَادِ مـن

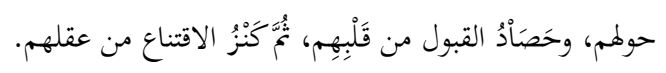

2- تحقيق معايير الذكاء العاطفي في السيرة النبوية (إمام الأَذِيَّاءٍ عاطفيَّا): وإن السابر الحكيم لأحداث السَّيرةِ النَّبَِيَّةَ وأحاديثها، يقع على سلسلة مطولة من المواقف والكلمات التي تتجلى

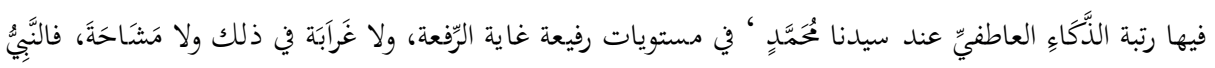

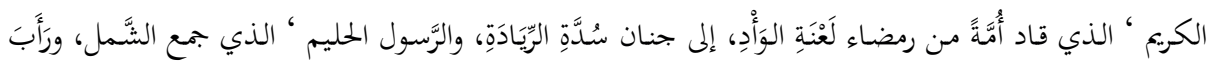

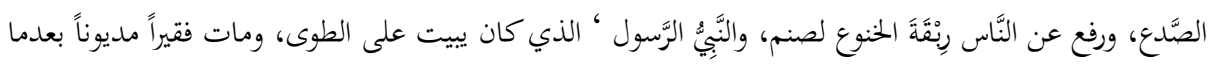

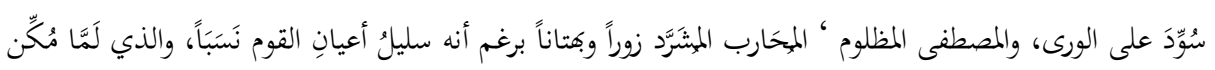

(1) الطبراني: 》المعجم الأوسط《)، باب العين، باب الميم من اسمه: عُمََّد، حديث: (5895). (2) ابن حجر العسقلاني: 》المطالب العالية《، كتاب الطب, باب حسن الخلق، حديث: (2626). 


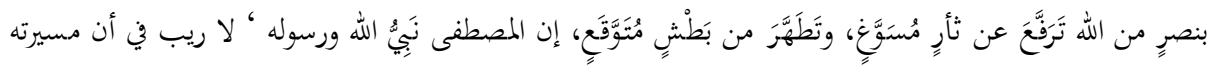

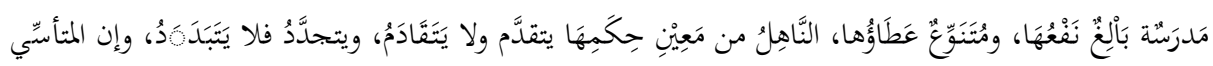
بمولانا مُحمَّدٍ " هو رجل متوازن في أفعاله، وذكِيٌّ في قراراته، قريب من الله، قريب من الناس. إن ما يسمى اليوم بالقرارات الاستراتيجية التي تترتب عليها بالسَّلب أو الإيجاب نتائج متناهية في العمق والشمول تنعكس على ماضي الأُمَّةَ وحاضرها ومستقبلها على حَدٍّ سواء، إن الإقدام على هذه القرارات المصيرية يكتاج من

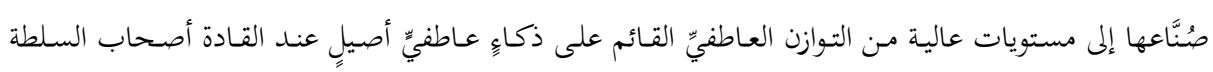
والتمكين. ولقد مرت على رسول الله أحداثُ جسامُ فُرِضَتْ عليه تَبَنَّ في ضوئها قراراتٍ خطيرةٍ وذلك بسبب دقتها، وشدَّة

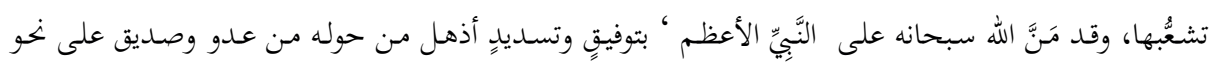

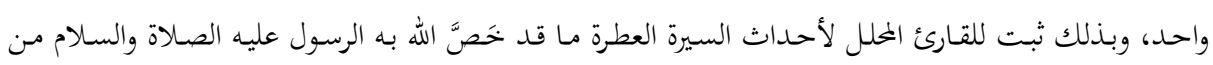
قدراتٍ نفسيةٍ متعددةٍ تمنَّلت في حزمة توازنٍ عاطفيٍٍ مكَّنه من قيادة جمهور الصحابة بحصافة، والتعامل مع كبواقمم

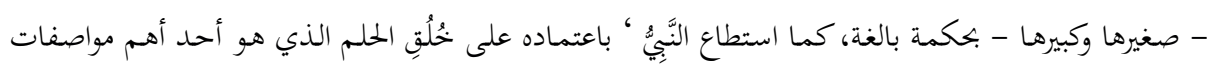

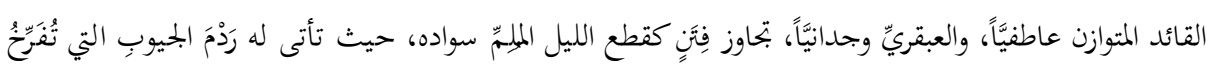
أوكاراً من الانقلابات والرّداتِ الهدَّامة، وتعبيد الطرق أمام من أراد أن يتوب إلى الله متاباً، ليغسل حوبته، ويتطهر من نقيصته، ويكفِّر عن صنيعته.

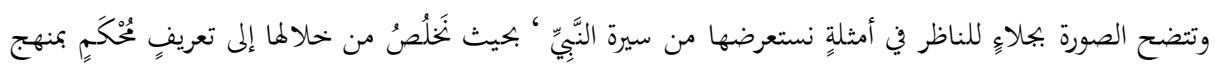
النُبوَّة التربويّ الرشيد في إدارة المخاطر، والتعامل مع المستحدثات من الأمور.

\section{3- توظيف منظومة الذكاء العاطفي في المراحل الدقيقة (النّفَاق... وِّرُرُ الخديعةِ وخندق}

أربابها):

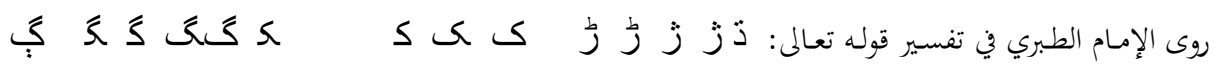

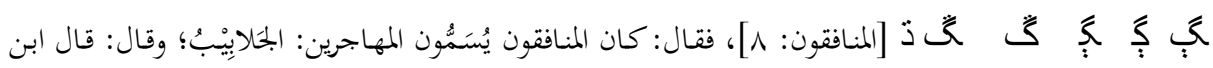

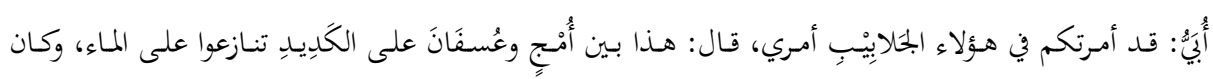

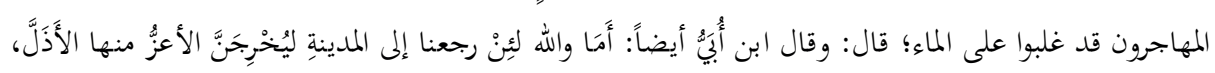
لقد قلت لكم: لا تنفقوا عليهم!، لو تركتموهم ما وجدوا ما يأكلون، ويخرجون ويهربون. 


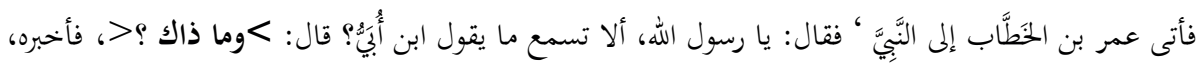

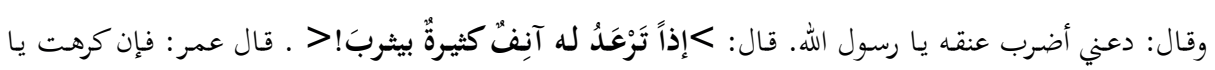
رسول الله أن يقتله رجل من المهاجرين، فَمُر به سعد بن معاذ، ومُمَمَّد بن مَسلَمَةَ، فيقتلانه فقال رسول الله ؛ > إني أكره أن يتحدث النَّاس أن مُحَمَّداً يقتل أصحابه، ادعوا لي عبد الله بن عبد الله بن أُبَيُّ> . فدعاه.

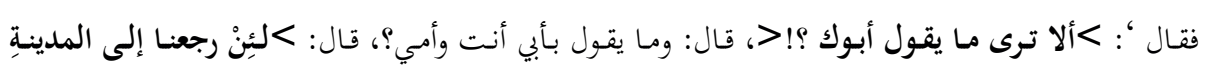

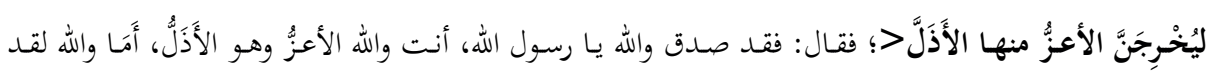
قدمت المدينة يا رسول الله، وإن أهل يثرب ليعلمون ما بها أحد أَبَرَّ مني، ولئن كان يرضي الله ورسوله أن آتيهما

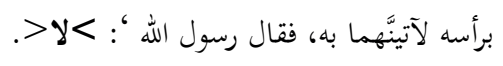

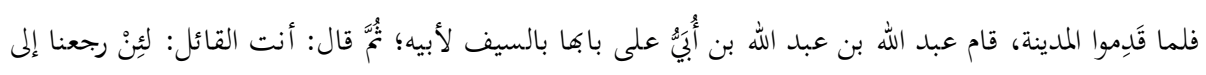

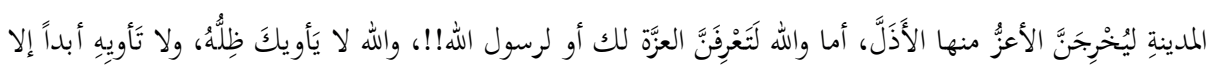
بإذٍٍ من الله ورسوله؛ فقال: يا للخزرج!!؛ ابني يمنعني بيتي!؛ يا للخزرج ابني يمنعني بيتي!، فقال: والله لا تَأويٍِِ أبداً

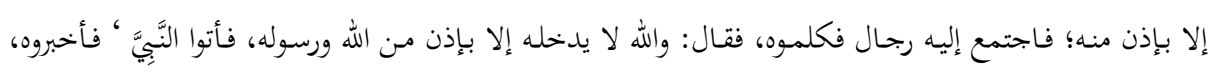

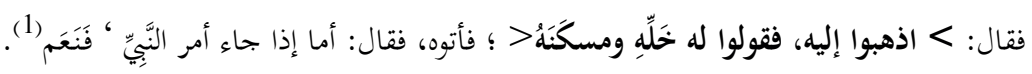
إن زعيم المنافقين عبد الله ابن أُبَيُّ أَقْدَمَ على خيانات عظمى استحق على كلِّ واحدةٍ منها منفردةً الحكمم بالإعدام دون أدلى تردد في مسألة قتله، أو أي وجهة اجتهادٍ قد تثير الاختلاف في أمر خيانته، وليس بخافٍ على أحسد

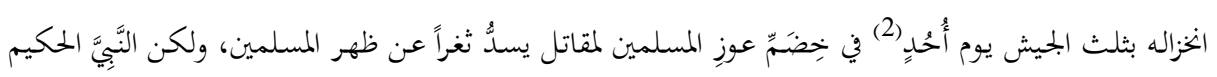

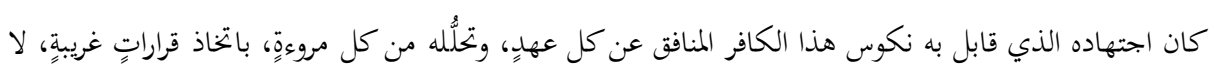

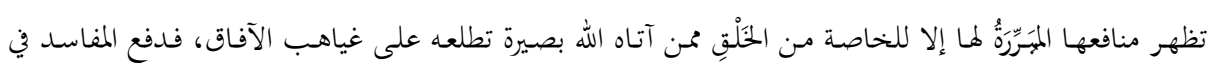

(1) الطبري: 》جـامع البيان في تأويل آي القرآن《، سورة المنافقون، القول في تأويل قوله تعالى:( يَقُولُونَ لَئِن

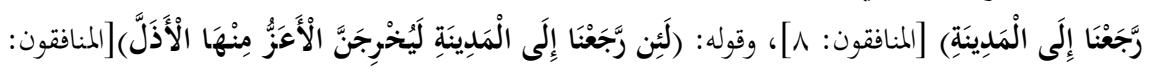

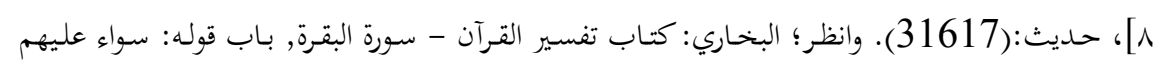

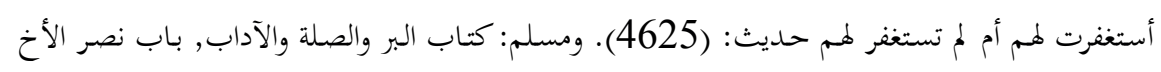
ظالماً أو مظلوماً، حديث: (4788). (2) الصنعاني: 》المصنف《، كتاب المغازي، وقعة أحد، حديث: (4733). (9433). 
فلسفة النَّبِّ ' السياسية مقدَّمة على جلب المصالح، وإن لكل مقامٍ مقالاً، وسيعلم الذين خحانوا قريباً جداً أي مصير ستؤول له أحوالهم، وذلك يمسُّهم رجس مـا صنعوا مـن قبائح الأعمال، إذاً إفها سياسـةٌ عسكريةٌ ذكيةٌٌ في إدارة الأزمات، تستبصر النتائج في ضوء المعطيات، وتتخذ القرارات بحسب الظروف المتاحة، إنه أعلى هرم يقيم عليه الأذكياءُ عاطفيَّاً، والمتوازنونَ وجدانيَّاً.

\section{4- التربية النبوية على الذكاء العاطفي الجماعي (ثُمَّ كان للنُّبُوَّةِ كلمتها):}

والمشهد التالي يبين وجهاً آخر للإقدام على جريمة الخيانة العظمى، غير أن الجحاني فيها صحابي بَدْرِيٌّ جليلِ،، خارت عزيمته، وتذبذب إيمانه، فسقط في وادٍ سحيقٍ جَرَّاء الغلط في التقدير، وسوء الأداء في الاجتهاد، ولكـن المنهج التربوي النبوي تضبطه خطوطُ عريضةٌ جليَّةُ، إذ تُذْهِبُ الحسنات فيه السيئات، ويُقَدََّمَ فيه العفو على العدل. أخبرنـا عبيد الله بن أبي رافع، قال: سمعت عليَّاً رضي الله عنه، يقول: بعثني رسول الله ، أنـا والزبير، والمقـداد بـن الأسود، قال: > انطلقوا حتى تأتوا روضة خَاخِ، فِإن بها ظَعِيَنَةً، ومعها كتاب فخذوه منها>>، فانطلقنا تعادى

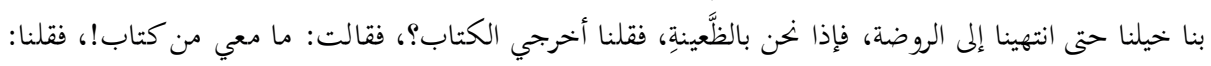

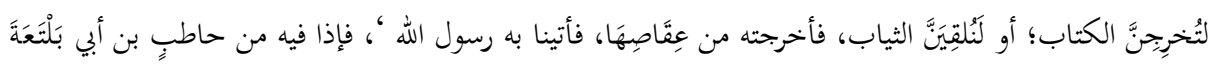
إلى أناس من المشركين من أهل مكة؛ يخبرهم ببعض أمر رسول الله ؛. فقال رسول الله ‘: >يا حاطب ما هذا؟>، قال: يا رسول الله، لا تعجل عليَّ إني كنت امرأ ملصقاً في قريش، ولم أكن من أنفسها، وكان من معك من المهاجرين لهم قَرَابات بمكة يحمون بها أهليهم وأموالهم، فأحببت إذ فاتني ذلك من النَّسَب فيهم، أن أتخذ عندهم يداً يحمون بها قرابتي، وما فعلت كفراً ولا ارتداداً، ولا رضاً بالكفر بعد الإسلام. فقال رسول الله ‘: >لقد صدقكم >، قال عمر: يا رسول الله دعني أضرب عنق هذا المنافق؟!، قال: >إنَّهَ قد

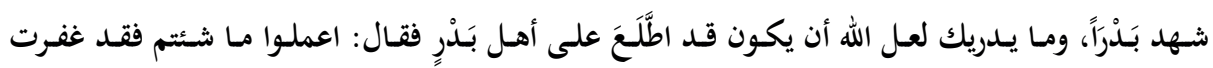
لكم إن الذَّكَاءَ العـاطفيَّ عند سيدنا رسول الله ،كان يمثّل صـمَّام الأمـان الذي يقيه مـن ردَّاتِ الفعل غير المدروسـة،

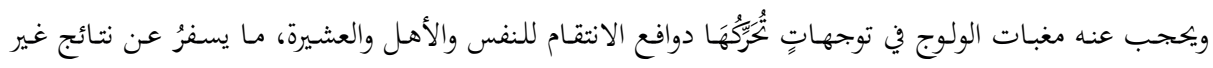
مرتقبة؛ قد لا يستطيع المرء ترميم آثارها الهدامة بأيِّ وسيلة متاحة، فتجاوزٌ عن مَكُرِ منافقِ أَشِرِ بغيةً ردمِ أوكارِ

$$
\text { (1) البخاري: كتاب الجهاد والسير، باب الجاسوس، حديث: (2866). }
$$


الفتنةِ التي سيتسبب قتله بفتح جحيم نارها، وصفحُ عن ذَنْبِ مؤمنٍ صادقٍ رجاء أن يفتح له الله أبواب التوبة المهشََََعَةِة آناء الليل وأطراف النهار.

5- تحصين الجماعة من الثفرق في ظلال مبادئ الذكاء العاطفي الراسخة (الشَّارِدُ والقِنْدِيل): ومن قطاف السيرة الشريفة في تبيان روائع ذكاءٍ رسول الله العاطفيِّ، يقصٌّ علينا الصحابي خَوَّاتُ بن جُبَيْرٍ لطيفةً

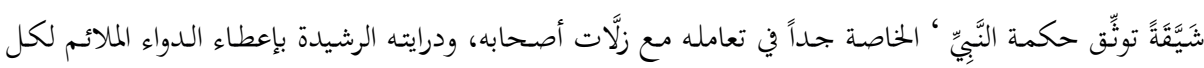

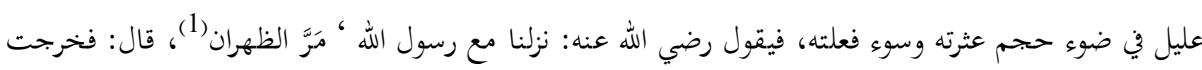

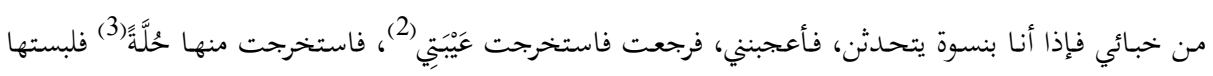
وجئت فجلست معهنَّ.

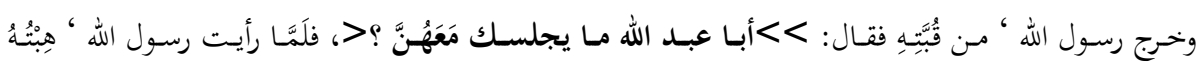

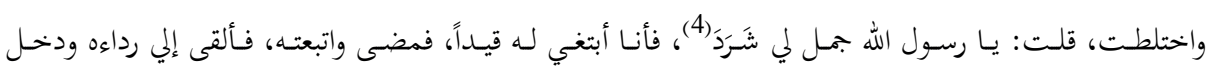

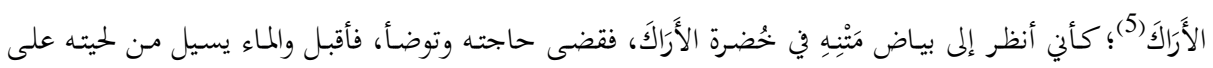

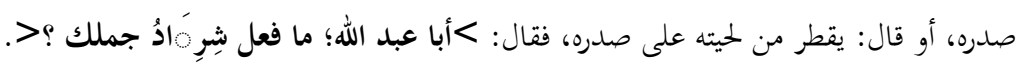

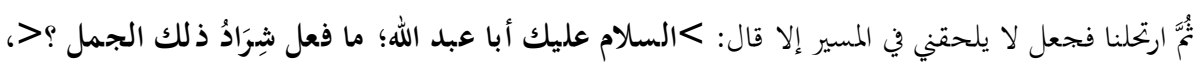
فلَمَّا رأيت ذلك تعجلت إلى المدينة، واجتنبت المسجد والمحالسة إلى النَّبِِّّ، فلَمَّا طال ذلك تحيَّنت ساعة خلوة المسجد، فأتيت المسجد فقمت أصلي، وخرج رسول الله ، من بعض حُجَره فجأةً فصلَّى ركعتين خفيفتين، وطوَّلت

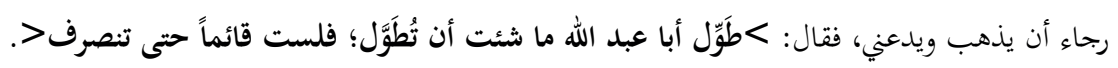

(1) مَرَّ الظهران: يسمى اليوم وادي فاطمهة، ويبعـد عن مكة (30) كِيلاً تقريبـاً، فيـه عـدد مـن القـرى أشـهرها (الجموم)

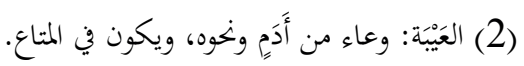

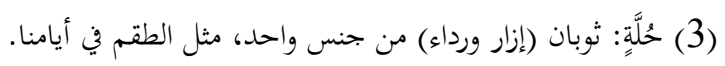

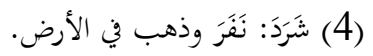

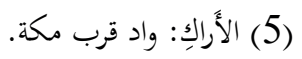


فقلت في نفسي: والله لأَعتذرنَّ إلى رسول الله ، ولأُبرئنَّ صدره، فلَمَّا قال: > السلام عليك أبا عبد الله؛ ما فول شِرَادُ ذلك الجمل ؟جا، فقلت: والذي بعثك بـالحق مـا شرد ذلك الجمـل منذ أسلم، فقـال: > رحمـك الله

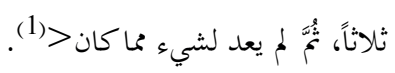
إن للسائل أن تدور في خلده استفسارات تتداعى على خاطره بعدما سمع قصة الصحابي خَوَّات، ومن ذلك أنه ربما يسأل كيف بتجرَّأ ذلك الصحابي على أن يقترف نظير ذنبه هذا؛ وهو في حضرة النُبوَّةَّة وسَدَنها؟

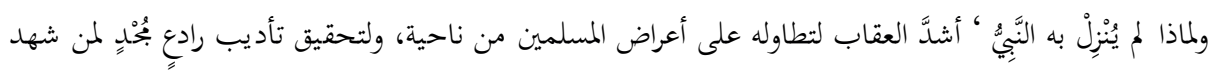
عذابه من المؤمنين؟

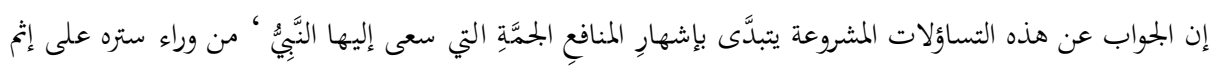

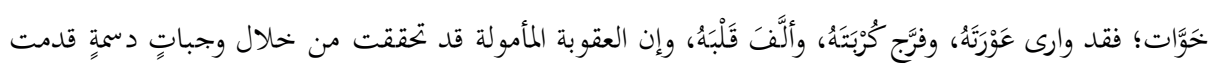
بالاعتماد على آليةِ من التقريع المستمر الموجَّهِهِ عبر منهج التذكير بالذنب المقترفِ، والتي بُذِلَتْ له على طبقِ من ذهبٍ؛ فاتنِ رونَقُهُ، ومُرِّ مذاقُهُ.

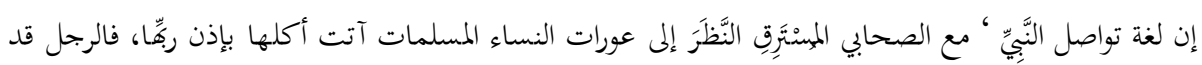
أسلم جَمَلَهُ، وآبَ إلى صاحبه مُعلناً أنه لن يعود إلى شروده الذي صادف - في غفلة العين المؤمنة عن أنوار خالقها - أن أنزل مطاياه بجوار مضارب العفيفات الطاهرات، إن هذا المنهج في التربية يمثّل أعلى نماذج الذَّكَاءِ العاطفيِّ الذي قـد يستضيفه المرءء بين ضفتي عقله وقلبه, (وإن هـذا التوازن الذي بلغ الغايـة والنهاية في دقة التمييز بين الأحوال المختلفة, وتوزيع المواقف المتضادة, بكسب طبيعة كل منها وظروفها ومقتضياتما بالحكمة والاعتدال, كيلا

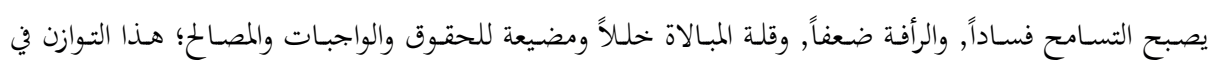
شخصية الرسول ' وسلوكه كان صورة تطبيقية دقيقة لذلك التوازن في الشريعة الكاملة التي جاء بها)(2).

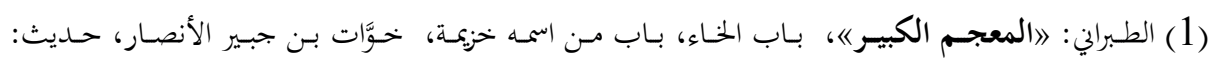

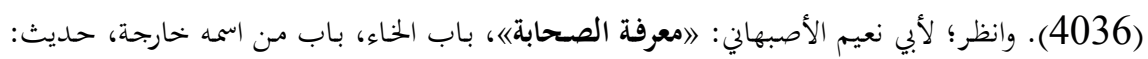

(2) مصطفى أحمد الزرقا: 》عظمة محمد خاتم رسل الله مجمع عظمات البشر《, (35). 
6 - - التوازن العاطفي لدى الصحابة الكرام (قَبَسُّ من أنوار الشَّيخين): إن في رجالات الصحابة الكرام نماذج حَيَّة توافق على تكامل توازفم النفسيِّ، وأَقَرَّر لهم باستقامة السيرة، وسلامة

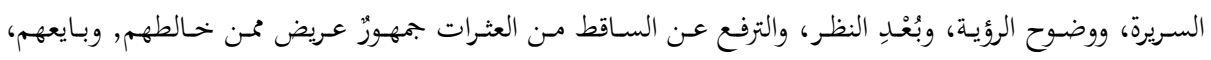
وشـاراهم، ونـاكحهم، وصَحِبَهُم في الإقامة والترحال، وقد تحقق ذلك لشريحة متنوعة ومتعددة من الصحابة مـن خلال توافق الأقوال مع الأعمال، وتباين المواقف في ضوء تغير المعطيات الملحوظة من ناحية، واختلاف مسببات الأحداث ونتائجها المتوقعة من ناحية أخرى. ويقع الدَّارس في ثنايا سيرة سيدنا أبي بكرِ الصِّدِّيق رضي الله عنه على لوحاتٍ فسيفسائيةٍ نَضرةٍ توثِّقُ امتلاكه لمراتب خاصة غاية الخصوصية من الذَّكَاٍِ العَاطِفِيِّ الفطريّ المنشأ بدايةً، والمكتسبَ التحسينَ والتطويرَ لاحقاً. فهو رجل قريب من الناس متعايش معهم برغم أشغالٍ شاغلةٍ ملقاةٍ على عاتقه ما أكثرها، وواجباتٍ عامةِ مناطةٍ برقبته ما أخطرها، إنه خبير في محاكاة آمال النَّاس وآلامهم، علماً أنه متكئُ في حصاد جميع هذا التوفيق على علاقةٍ متينةٍ تربطه بخالقه سبحانه وتعالى. ومما يجلِّي تكامل شخصيته في علاقته مع ربه وعباده سبحانه ما رواه أبو هريرة عن رسول الله ‘ قال: > من أصبح منكم اليوم صائماً ؟>> قال أبو بكر: أنا، قال: > فمن تبع منكم اليوم جنازةً ؟>، قال أبو بكر: أنا، قال: >فمن أطعم منكم اليوم مسكيناً ؟>> قال أبو بكر: أنا، قال: >فمن عاد منكم اليوم مريضاً؟>، قال أبو بكر: أنا، فقال رسول الله: >ما اجتمعن في امرئ، إلا دخل الجَنَّة>(1).

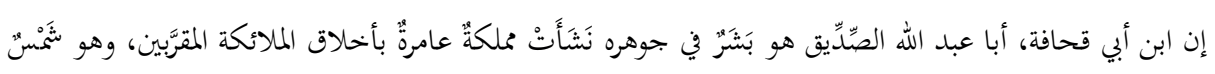
تشرق بأنوارها على النَّاس لتغمرهم عافيةً ونوراً، وهو قمرٌ يأنسُ بِوَجْدِهِ الغرباء والحيارى فيكسو ليلهم فرحاً وذكراً.

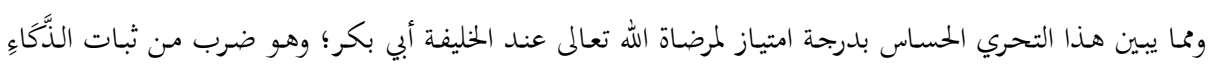

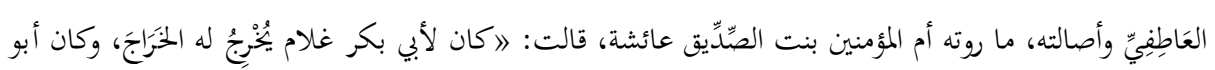

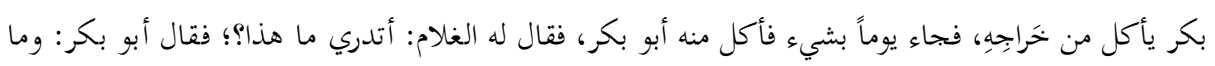
(1) ابن حجر العسقلاني: 》المطالب العالية《، كتاب الطب، باب حسن الخلق، حديث: (2626). 
هو؟؟ قال: كنت تكهُّنت لإنسان في الجماهلية، وما أُحْسِنُ الكهانة، إلا أني خدعته، فلقيني فأعطاني بذلك، فهذا

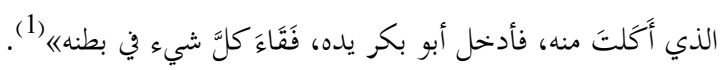
أليس رغيف الحبز الحلال، يعمر أجساد البشر، ويحفظ عليهم بركات العمر؟!، وإن من يتحرى القرش المباح يجمعه،

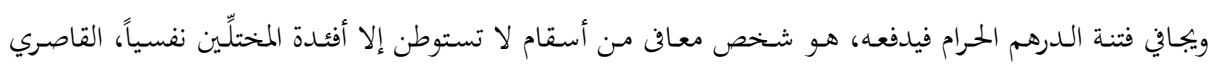
البصر، والمطموس على بصيرقم.

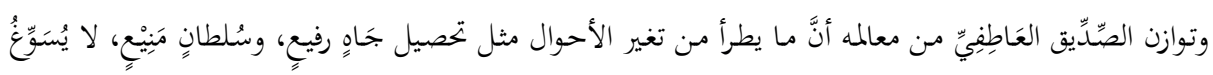

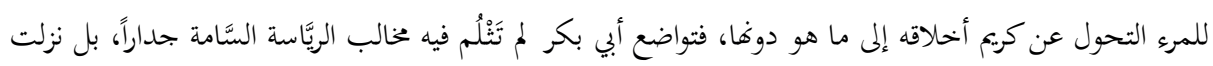

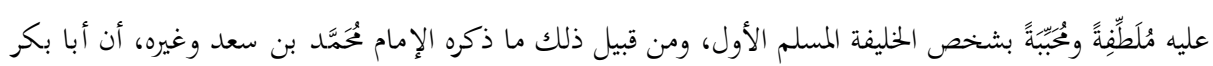

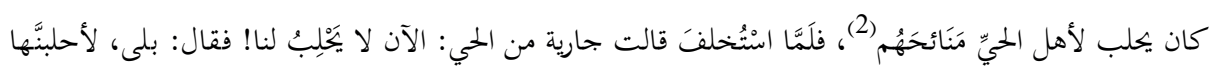

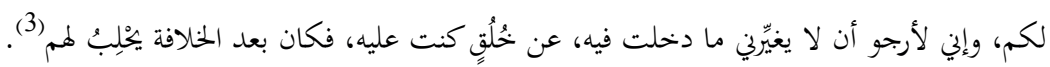
إن الثبات على المبادئ المعتنقة، مؤشر ذو دلالة إيجابية على أصالة خصلة الوفاء، ومتانة شنميلة قوة الانتماء، وهي تمثل أحد معايير الحكم على المرء المتوازن في عواطفه، الذي لا يستقيم بحال أن يغدو دمية متحركة تعبث به حتى النسائم اللطيفة الرقيقة.

وللخليفة المسلم الثاني حكاياتُ أخرى تؤكد تربُعَ هذا الرجل العظيم على سُدَّةٍ البشر المتوازنينَ نفسيَّا، والأذكِياءِ

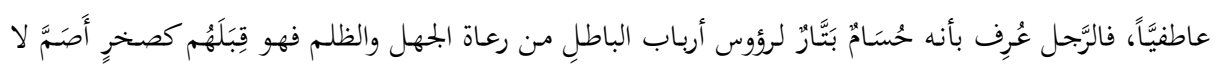

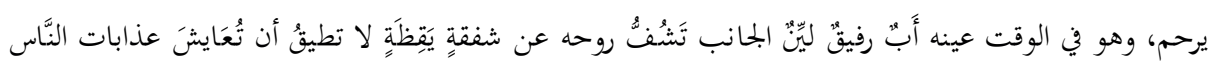
وأحزانم. إن طبيعة شخصية الفاروق بتعل المتابع لسيرته الحافلة بالإبحازات يقف حائراً عند مواقفه المتباينة بعمق في الشكل

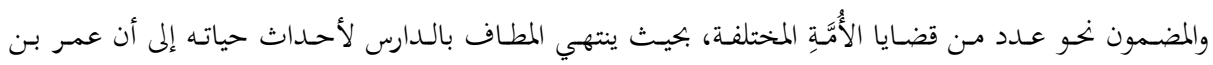
الخَطََّب كان يتمتع بقدرات مذهلة تُعِينُّهُ على ترتيب الأوراق المبعثرة، واستثمار الأوقات المهلدورة، ومداواة النفوس المعتلَّة، وتقويم مسار الممارسات المحرمة.

$$
\begin{aligned}
& \text { (1) البخاري: كتاب المناقب، باب أيام الجاهلية، حديث: (3652). }
\end{aligned}
$$

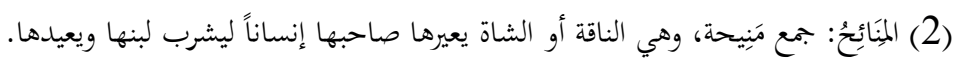

$$
\begin{aligned}
& \text { (3) عبده كوشك: 》صفحات مشرقة من تاريخ أعلام الأمة/، (ص/212 - 13). }
\end{aligned}
$$


وإن في قصة خروج عمر إلى الشام عِبَراً ودلالاتٍ تُشَخٌُِّ مستوى وضوح الرؤية عند أبي حفصٍ، فلا عدول عن الأصول إلى القشور، ولا وجود لأيِّ فرجة قد يَلِجج منها الشيطان إلى النَّفس التي أبصرت طريقها، فالمعادلة سهلة للغاية: إن شرف الانتساب إلى الإسلام أرفع الأوسمة، وما خلاه بهرجٌ دنيويٌٌ وضيعُ لا يبرحُ سرابه أن يتبدَّدَ مع بارقةٍ

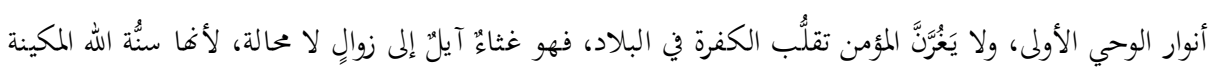
ومن يطيق لِِسُنَّة الله تبديلاً أو تحويلاً.

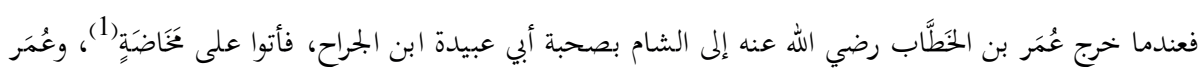
على ناقة له فنزل عنها وخلع خفيه فوضعهما على عاتقه، وأخذ بزمام ناقته فخاض بها المخخَاضَة، فقال أبو عبيدة: ايا أمير المؤمنين أنت تفعل هذا، تخلع خفيك وتضعهما على عاتقلك، وتأخذ بزمام ناقتك، وتخوض بها الميخَاضَّ؟

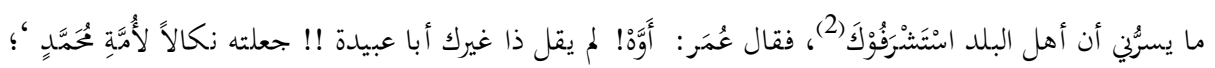
إنا كنا أذل قوم فأعزنا الله بالإسلام، فمهما نطلب العزة بغير ما أعزنا الله به أذلنا اللهی) (3). والرجل الذي كان سفير قريش في الجاهلية إلى النَّاس، وغدا سفير المسلمين إلى المحد في الإسلام، والذي أرعب ذكره قلوب عتاة الروم والفرس، وأهرمت أصداء قرعه طبول الحرب عزيمة نُجْبَة الفرسان، وأذهلت أخباره الشيوخ والأطفال

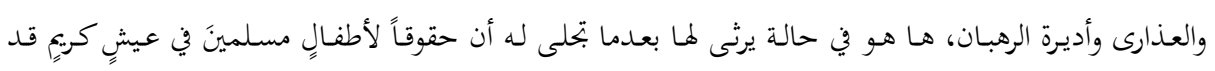

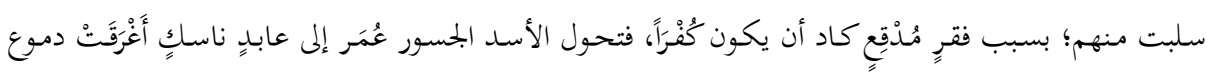

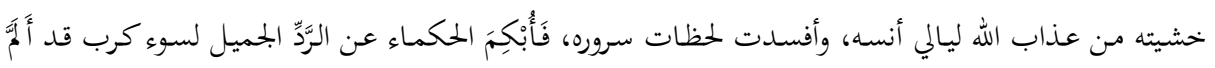
بعملاق الإسلام.

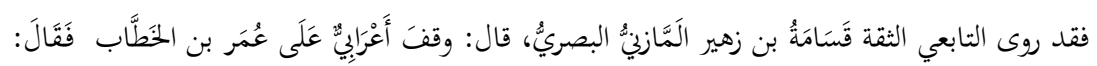

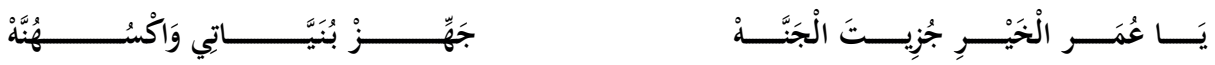

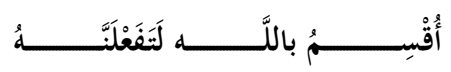

(1) المِخَاضَةُ: الموضع القليل الماء الذي يعبر فيه النَّاس مشاةً وركباناً.

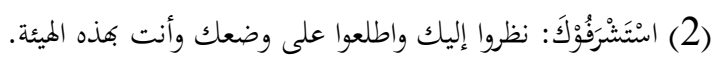
(3) الحاكم: 》المستدرك على الصحيحين《، كتاب الإيمان، وأما حديث سمرة بن جندب، حديث: (191) (19). 
قال: فإن لم أفعل يكون ماذا يا أعرابيٌُ؟ قال: أقسم بالله لأمضينَّه. قال: فإن مضيت يكون ماذا يا أعرابيُّ؟ قال:

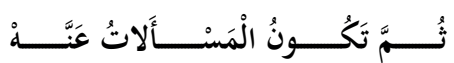

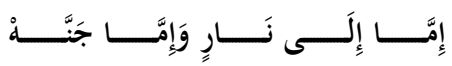
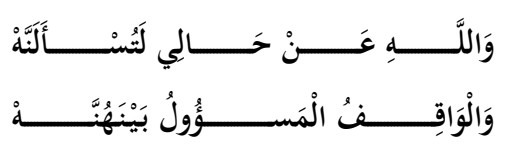

قال: فبكى عُمَر حتى اخضلت لحيته بدموعه، تُمَّهَ قال: يا غلام، أعطه قميصي هذا، لذلك اليوم لا لشعره، والله ما أملك قميصاً غيره! (1). وروى زيد بن أسلم أيضاً ما يتناسب مع هذا المقام من حالة الطمأنينة والسكون التي كانت عند أمير المؤمنين، عن أَبِيهِ أن عُمَر بن الخَطَّبَ طاف ليلة، فإذا هو بامرأة في جوف دار لها وحولها صبيان يبكون، وإذا قِدْرُ على النار قد

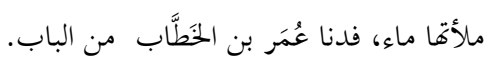

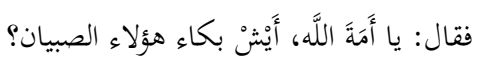

$$
\text { ققالت: بكاؤهم من الجوع. }
$$

فقالت: قد جعلت فيها ماء أعللهم بها حتى يناموا، أَوْهمهم أن فيها شيئاً من دقيقِ وسمنٍ.

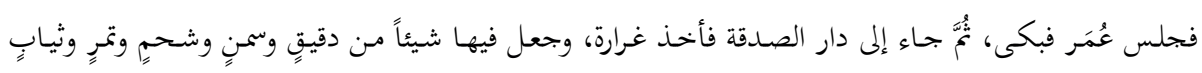

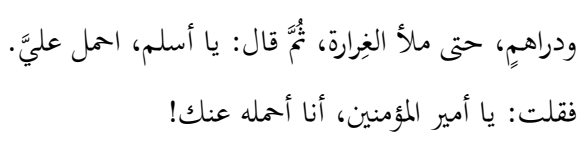

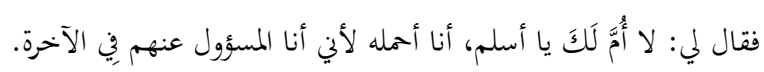
قال: فحمله على عنقه، حتى أتي به منزل المرأة، قال: وأخذ القدر، فجعل فيها شيئاً من دقيقٍٍ وشيئاً من شحمٍ وتمرٍ، وجعل يحركه بيده وينفخ تحت القِدِرِ، قال أسلم: وكانت لحيته عظيمة، فرأيت الدخان يخرج من خلل لحيته،

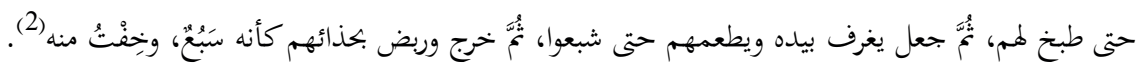

$$
\text { (1) (1ابن الأثير: أسد الغابة《، ( 662/3). }
$$

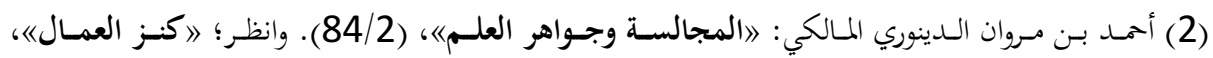
(148/12). و (الرياض النضرة في مناقب العشرة《، (385/2). 
إن من أهم مصادر تحصيل السعادة هو ( سعي الإنسان لإسعاد الآخرين، وبخاصة من يحتاجون إليه من الضعفاء والفقراء، وهؤلاء هم المصدر الأهم للإسعاد، ولا شيء يسعد الإنسان كشعوره بدوره في إسعاد الآخرين، ومن يشعر بالشقاء فعليه أن يجرب هذا الأسلوب، وسوف يجد لذة دائمة في حياته، وهي لذة متجددة في كل صباح، والأنانية تبعد الإنسان عن هذا الاختيار) (1).

\section{7- التوازن العاطفي لدى الصحابة الكرام (فقه الحُبّ القويم):}

إن الصدق في المعاملة، والتراحم والتعاطف بين إخحوة الإسلام، وبذل النصيحة الخالصة لوجه الله سبحانه وتعالى، هي ممارسات تدلل بجلاء على تمتع صاحبها بتوازن نفسي محمود، نابع عن ذكاءٍ عاطفيٍٍ راسخٍ في النَّفس ومتحذِّرٍ في الإدراك، وإن هذه التربية الرشيدة التي تعهد بها النَّبٌُ ، الرعيل الأول مـن الصحابة آتت أكلها حقائقَ متلألئةً

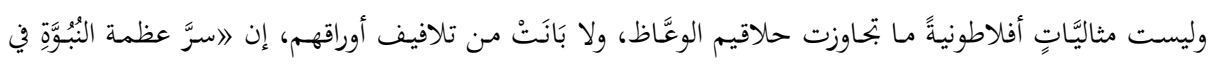

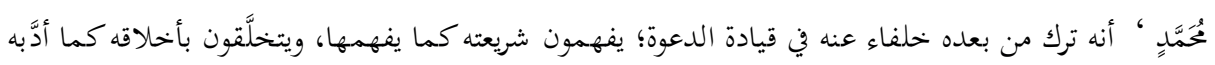
ربُّه، فاستمرَّت الدعوة من بعده، وأدت رسالتها في التاريخغ (2). ومن فتوحات الله جلَّ وعلا على رعيل القرن الأول من المسلمين في موضوع حسن الخُلق ما حدثنا به أبو حمزة أنس كن

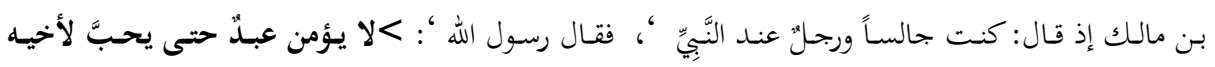
المسلم ما يحبُّ لَنَفْسِهِ>> قال أنس: فخرجت أنا والرجل إلى السوق فإذا سلعة تباع فَسَاوَمْتُهُ، فقال: بثلاثين، فنظر الرجل فقال: قد أخذهما

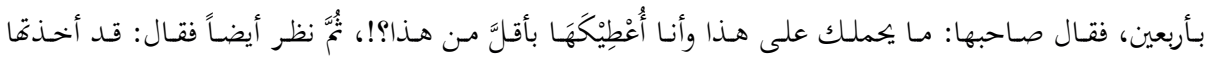
بخمسين، فقال صاحبها: ما يحملك على هذا وأنا أُعْطِيْكَهَا بأقلَّ من هذا؟ قال: إين سمعت رسول الله ، يقول: >لا يؤمن عبد حتى يحبَّ لأخيه ما يحبُّ لنفسه> وأنا أرى أنه صالح بخمسين (3).

(1) محمد فاروق النبهان: 》خواطر مضيئة من وحي الأيام《، (132). (2) مصطفى السباعي: 》ادروس من الحياة《، (202).

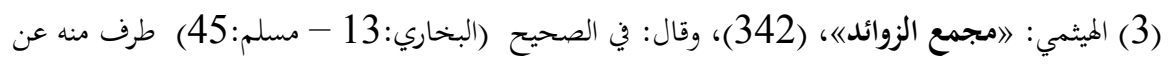

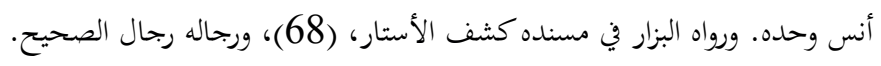




\section{8- 8 - التوازن العاطفي لدى الصحابة الكرام (بصيرة الوَلَّدِ والأُمِّ):}

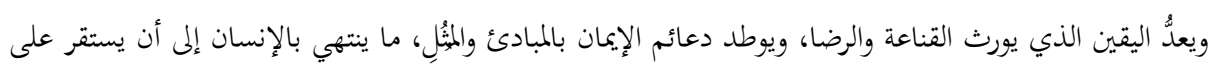

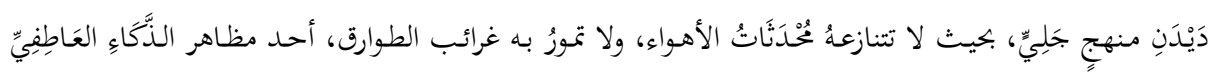
البَّنَاء، وأهم ثمرات الطمأنينة النفسيَّة الصحيَّة. وفي بحريات الحادثة التالية إيمان عميق بالقضاء والقدر، وثقة بالغة بأن ما عند الله قادم لا شك في بحيئه ولا ريب، لميك، ويتجلى ذلك في سلوك الابن الصالح، ومعه الأم المستبشرة بما عند الله خيراً.

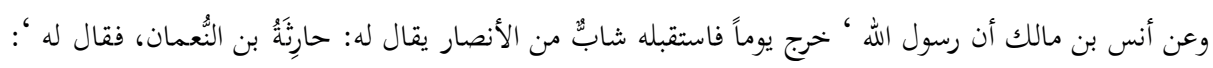

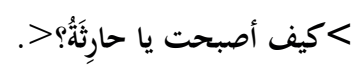
قال: أصبحت مؤمناً حَقَّاً.

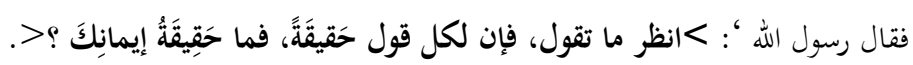

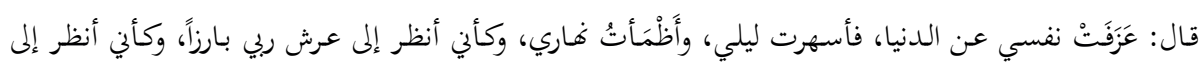

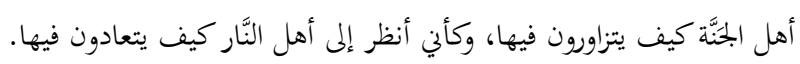

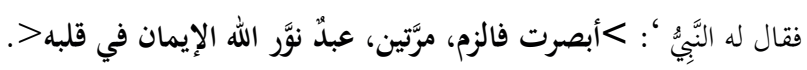

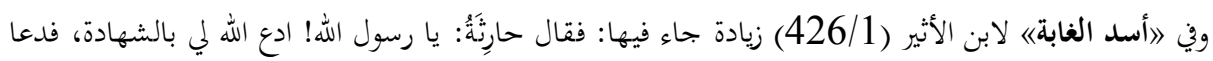

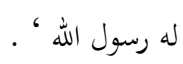

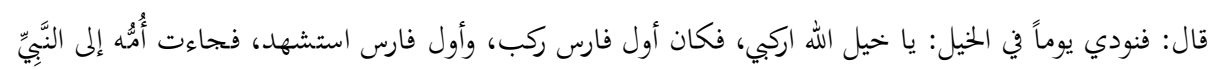

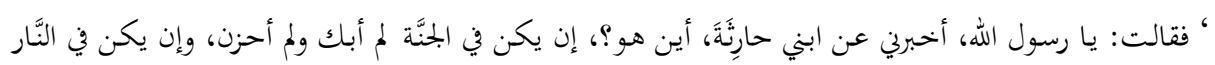
بكيت ما عشت في الدنيا؟!.

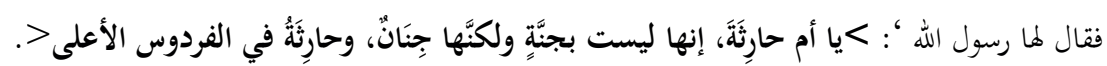

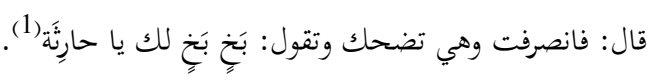

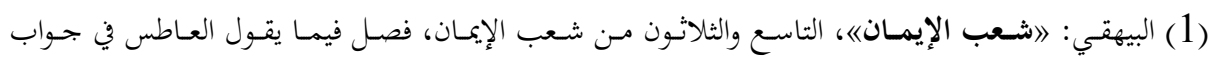

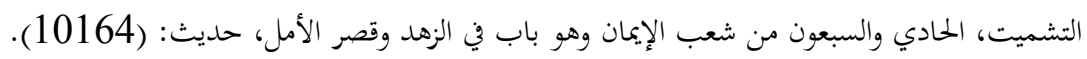


إن الثقة بما عند الله تورث المرء حالة من التوكل عليه وحده سبحانه، بكيث تجعله في طمأنينة وسكينة وحبور، وإن

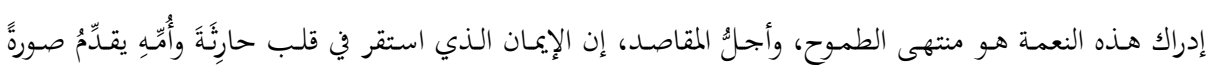
مشرقةً لأثر اليقين في نفوس النَّاس وأنشطتهم الحياتية المختلفة، ويعد التوكل من أبخع سبل علاج القلقِ السبِي الهدَّام الذي يفضي في أحياٍٍ كثيرةٍ إلى أدواءَ نفسيةٍ حرجةٍ مثل الاكتئاب, وضيق المحالس, ورهـاب المرتفعات, والعزلة المرضية, والوسواس القهريّ. إن المتوكلين على الله تعالى هم أشخاصٌ متوازنونُ عاطفيًا، تعرفهم بعلامات الرضا عن الله تعالى المتجلِّية في تعابيرهم

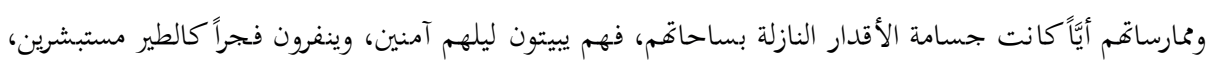
ويصدُقُ فيهم قول أبي الطيب:
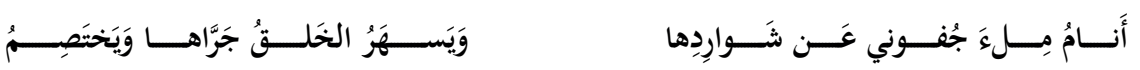

وإن أعلى درجات النِّمِم التي منحها الله عبداً من عباده تتمثل في سعادةٍ غامةٍ تقطن شغاف القلوب، تربو بجوهرها

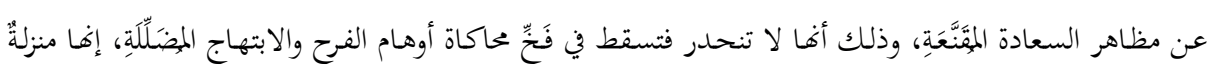
رفيعةٌ دونها جميع المنازل، وغايةٌ ساميةٌ ليس لها من دون الله مُنْعِمْ.

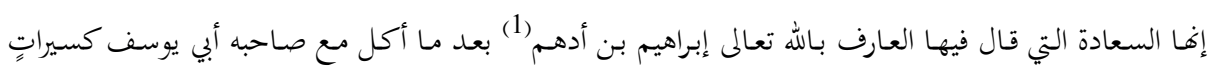

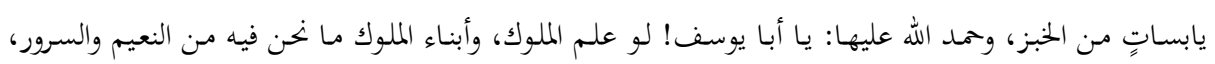
لجالدونا بالسيوف أيام الحياة على ما نحن فيه من لذيذ العيش وقلة التعب (2).

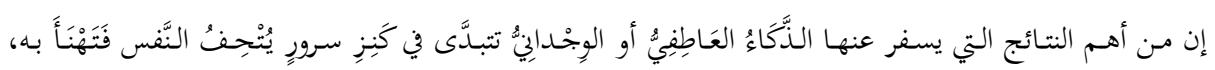

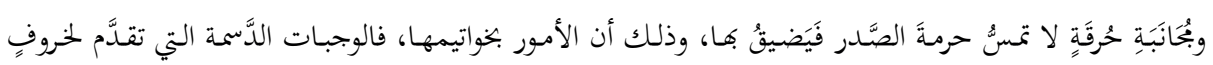

(1) هو إبراهيم ابن أدهم البلخي، بحاهد، سيد الزهاد، أحد السادة الأخيار والعباد الأطهار، ولد في حدود سنة

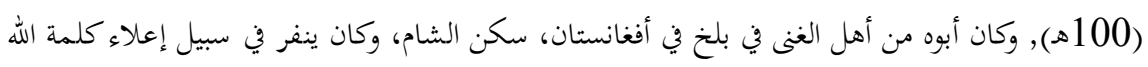
مع المحاهدين ضد الروم.

(2) البيهقي: (الزهـد الكبير)، (81). وانظر؛ ابن عساكر: 》اتـاريخ دمشق《،، (302/6 - 303، 365 - 


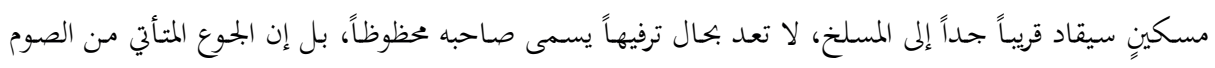

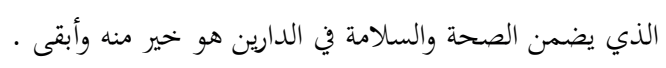

\section{9- التوازن العاطفي لدى التابعين الكرام (عَابِدةُ الإسلام الأولى):}

وإننا في ضيافة مدرسة العابدة الزاهدة الذاكرة رَابِعَة بنت إسماعيل العَدَوِيَّة، أم عمرو، مولاة آل عَتِيك، بنت البصرة، سوف ننهل من الراحة بذكرها ما لا يتخافت نَغَمُهُ، ونَستقي من مَعينِ الحَب لله ورسوله ما يدوم وَجْدُهُ، إفها امرأة

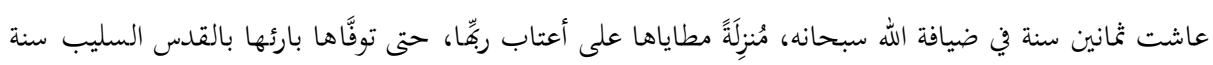

ومن لطائف أخبارها المحببة إلى قلوب المؤمنين ما حدث لها مع الإمام الأعظم سفيان الثوري يوم لقي رَابِعَةَ العَدَوِيَّة،

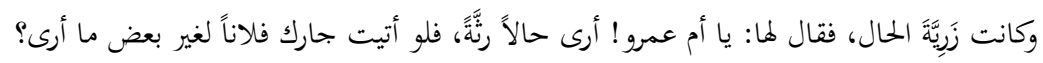

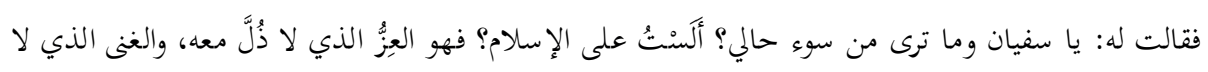
فقر معه، والأنس الذي لا وحشة معه.

واللإ إني لأستحيي أن أسأل الدنيا من يملكها، فكيف أسألها من لا يملكها؟! فقام سفيان وهو يقول: ما سمعت مثل هذا الكلام.

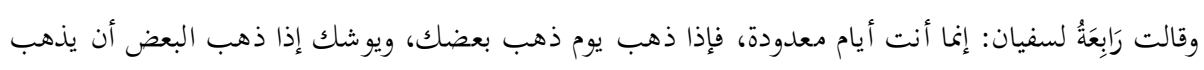
الكلُّ وأنت تعلم، فاعمل. ومن روائع سكوفا الروحي حيث لا وجود لخوفٍ مرضيٍ يجتاح فرائصها، ولا ليأسِ يُلُّك أسوار طمأنينتها النفسية،

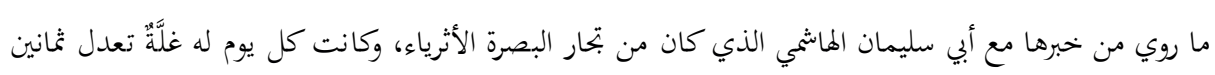
ألف درهم.

فبعث إلى علماء البصرة يستشيرهم في امرأة يتزوجها، فأجمعوا على رَابِعَةَة العَدَوِيَّة، فكتب إليها: اأما بعد: فإِن مُلْكِي مسن غلَّة الدنيا في كل يوم ثمانون ألف درهـم، وليس يمضي إلا قليل حتى أتمّهَا مئة ألف إن شاء الله، وأنا

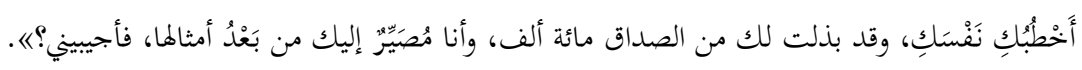
فكتبت إليه: اأما بعد: فإن الزهد في الدنيا راحة القلب والبدن، والرغبة فيها تورث الهم والحزن، فإذا أتاك كتابي

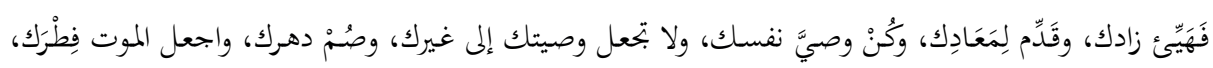
فما يسربي أن الله خوَّلني أضعاف ما خوَّلك، فيشغلني بك عنه طرفة عين، والسلامهـ. 
وقالت مرة امرأة لرَابِعَةً: إني أحبك في الله، فقالت لها: أطيعي من أحببتني له. وكانت رحما الله تقول: اللهم قد وهبت لك من ظلمني، فاستوهبني ممن ظلمته. وأورد لها الشيخ شهاب الدين السهرورديُّ في كتابه 》عوارف المعارف《 نشيدها الروحي الخالد:

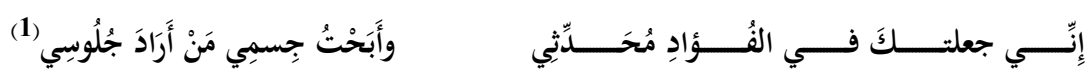

إن السعادة في الدارين هي غاية كل مؤمن، وإن أسعد امرأة في الدارين رَبِعَة، فقد أبصرت هذه العابرة أنوار الله شاخصةً، فما تضيرها بعد كل هذا الأنوار ظلماتُ، عرفت طريق الحُسْنِ والبَهَاءٍ فاكتحلت في مرة ذكراً، وفي أخرى كان قيامها الليل تكريماً وتشريفاً.

10-التوازن العاطفي لدى الصحابة الكرام (حَمَّاد.. نموذج العَالِمُم العَامِلُ): ونستكمل مشـوارنا الإيماني مـع السادة الشـفاء المكرمين في الـدنيا والآخرة مـن الذين صدقوا الله في بيعتهم على

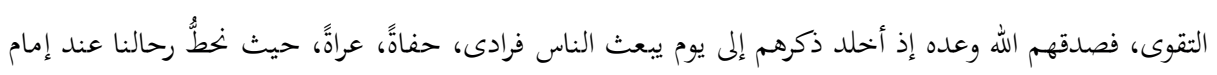
كبير في تعليم سبل كسب اليقين والرضا، وطرائق حيازة السعادة والهنا، والتي هي غاية كل نفس، وأمل كل عابر سبيل، إنه الحافظ القدوة، أبو سَكَمَةَ البصريُّ، حَمَّادُ بن سَكَمَةَ، مفتي البصرة، الذي كان سيد أهل زمانه، ورأساً في السُنَّة، من الأخيار بحابي الدعوة، وقد كثرت أخباره المثيرة للدهشة في الزهد والعلم والتنزُّه عن سفاسف الأمور،

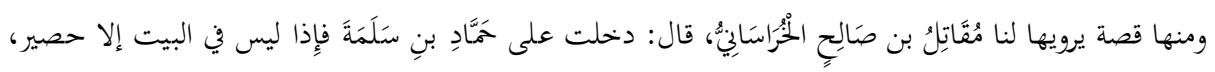

(1) ابن خلكان: 》اوفيات الأعيان وأنباء أبناء الزمان《، (285/2 - 288). وانظر: 》اسير أعلام النبلاء《،

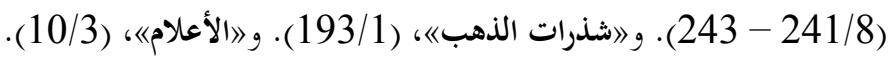




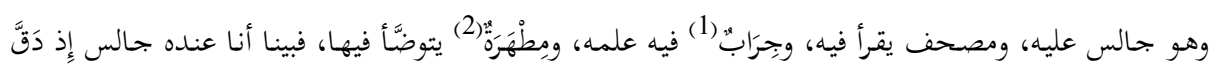

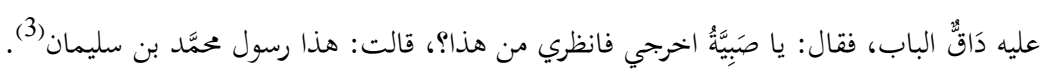
قال: قولي له يدخل وحده، فدخل، فسلَّم، وناوله كتابه، فقال: اقرأه، فإذا فيه:

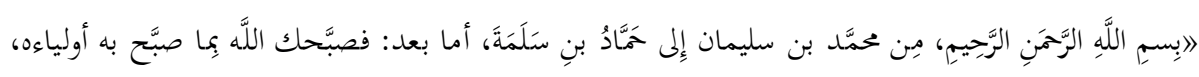
وأهل طاعته، وقعت مسألة، فأتنا نسألك عنها، والسَّلامهام.

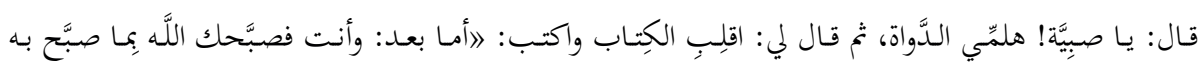

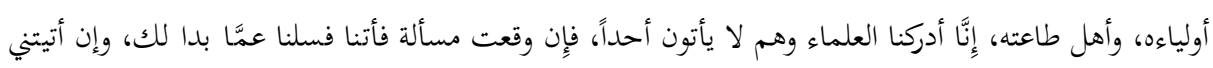
فلا تأتني إلا وحدك، ولا تأتني بخيلك ورجلك، فلا أنصحك ولا أنصح نفسي، والسَّاملامه .

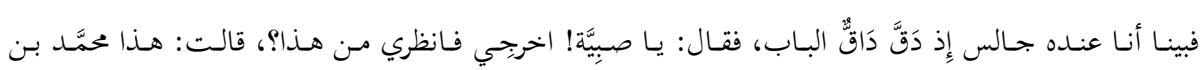

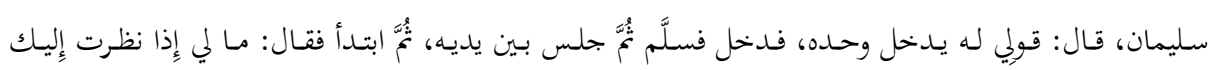
امتلأت رعباً?

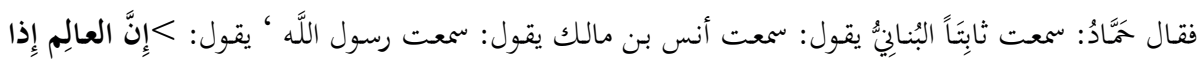

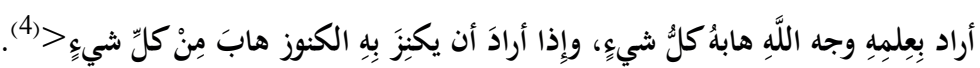

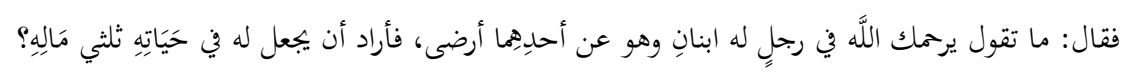

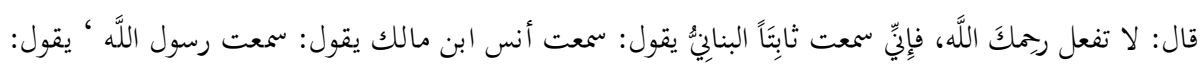

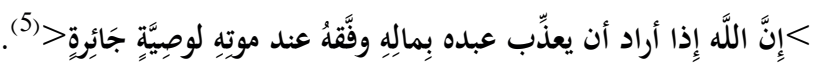
قال: فحاجة إليك؟

(1) والجرِّاب: وعاء يحفظ فيه الزاد ونحوه.

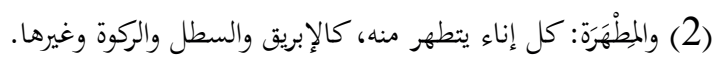

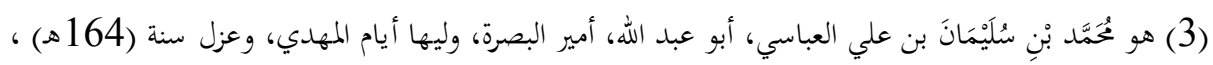
وأعاده الرشيد، وزوجه العباس بنت المهدي سنة (172هـ)، واستمر في البصرة إلى أن توفي سنة (173هـ).

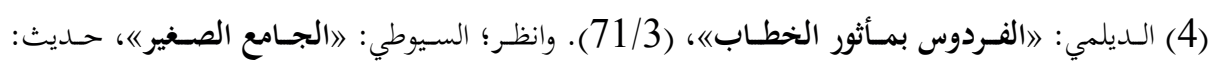
(5657) (5) الديلمي: المرجع السابق، (244/1). 


\section{قال: هاتِ، ما لم تكن رزِِّة فِ دِينٍ.}

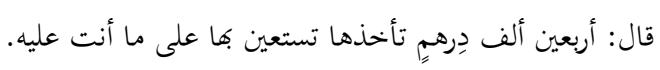
قال: ارددها على من ظلمته بها. قال: والله ما أعطيك إلا ما ورِثنه. قال: لا حاجة لي فيها، ازوِها عنبّ زوى اللَّه عنك أوزارك. قال: فغير هذا. قال: هاتِ، ما لم يكن رزِيَّة في دِينٍ. قال: تأخذها فتقسمها. قال: فلعلّي إِن عدلت في قسمها أن يقول بعض من لم يرزق منها: إِنَّه لم يعدِل في قسمها فيأثم، ازوِها عتيّي زوى اللَّه عنك أوزارك (1). - (1) إن النَّفس المؤمنة تستقرئ في ظلال الذَّكَاءِ العاطفيِّ المتين المستقبل على بصيرة، وتُعمِلُ العقل في المسائل المعروضة

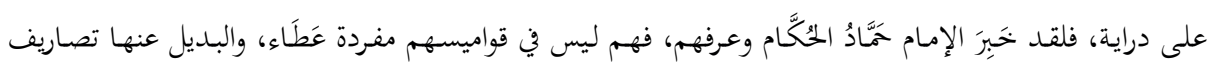
مبتكرة كثيرة وشاذة حتماً لمفردة أَخْذ، إن أموال الله التي سلَّطهم عليها هي محجوبة عن أن يصرف قرش واحد منها لوجه الله وحده، إن المال السياسي كان وسيبقى يُمنْحُ لتحقيق مصالح وشراء ألسنٍ وأقلامٍ ومواقف، وذلك بغية أن يستر فيها الحاكم جَوراً، أو يدفن مظلمةً، وهذه التجارة الرابحة المباحة في شريعة الحكام معاذ الله أن بحد أعشاشاً تُفرُِِّّ فيها بيوضها القاتلة على مرتفعات العارف بالله العالم العامل حََّّادِ بن سَلَمَةَ رحمه الله تعالى، وإن النفس التي تقارع مغريات الدرهم والجماه, ومفاتن النساء ذوات المنصب والجمال هي نفس تتوضَّع على هرم النفوس المتوازنة عاطفياً.

\section{1-منظومة الذَّكَاءُ العَاطِفِيٌُ الجماعيُّ:}

وفي ظلال ما أفدناه من إشراقات بعض روائع أحداث تراثنا الإسلامي المجيد، بنتهد رأينا في أن نختم بهذه الأسئلة الواضحة:

(1) الخطيب البغدادي: 》الجامع لأخلاق الراوي وآداب السامع《، (362/1 - 363). وانظر؛ ابن عساكر، 》اتاريخ دمشق《، (132/53 - 133). وابن الجوزي: 》اصفوة الصفوة《، (361/3 - 362). 
كيف استطاع الإسـلام أن ينمِّي مهارات الذَّكَاءِ العَاطِفِيِّ عند الرَّعيل الأوَّل مـن الصَّحابة والتَّابعين، فانتقلوا مـن الضَّياع إلى الهداية، ومن الضَّعف إلى القوَّة، ومن التَّرُُق إلى الوحدة، ومن التَّبعية إلى القيادة؟

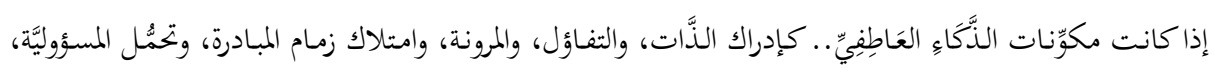
والقـدرة على التواصل مـع الآخرين، والإيمان بثقافة الاختلاف البنَّاء، وإتقان سياسة إدارة الأزمات، وغير ذلك

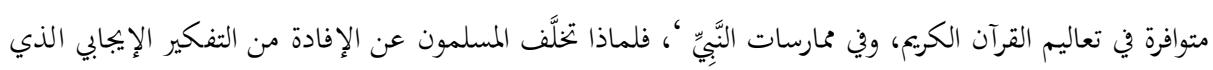

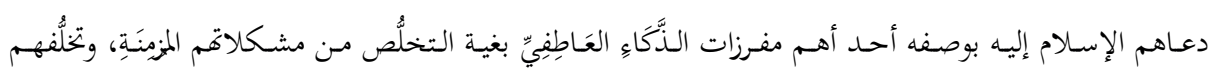
الخطير؟

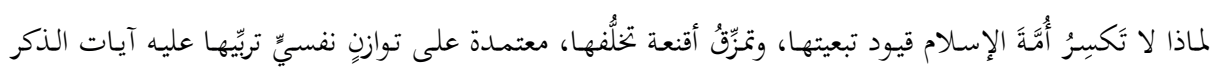
الحكيم، وسيرة النَّبِّ الأمين؟ وإن القصد السامي من وراء طرح جملة الأسئلة الكبيرة تلكم هو أمل حزين له نحيب يدمي القلوب، ننشد مـن

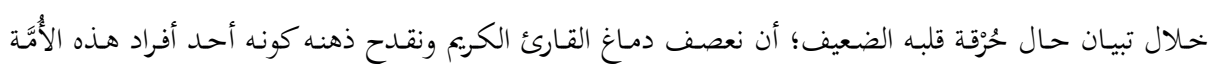
المنكوبة بتكالب لقطاء العالم كافةً عليها(1)، تاركين بين أياديه النازفة أوراقاً بيضاء رجاء أن يدوّّن عليها إجاباتٍ

(1) تنادى عتاة الغرب والشرق في القديم والحديث من الأيام بغية شن حرب على الشريعة الخاتمة، متجاوزين لإبحاز فمهم المشين جميع خلافاقم العميقة، فقد سئل وزير خارجية إيطاليا عندما كان رئيساً للمجموعة الأوربية:

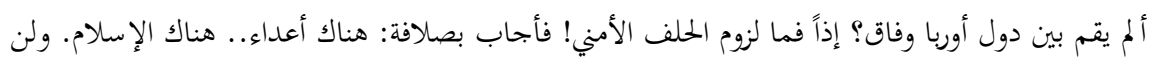

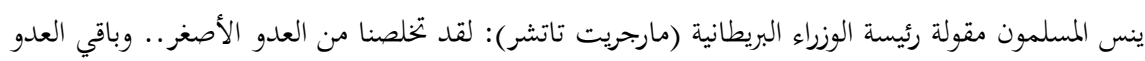
الأكبر وهو الإسلام. وقد قال (آلان موهيد) في كتابه الشهير 》النيل الأبيض): إن احتلال الإنحليز لمصر في

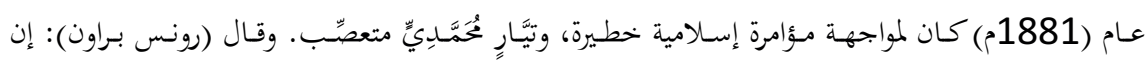
الإسلام هو الجدار الوحيد في وجه الاستعمار الأوربي. وقال (بن جوريون) رئيس الوزراء الإسرائيلي: اصبروا..

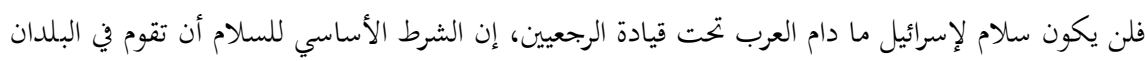

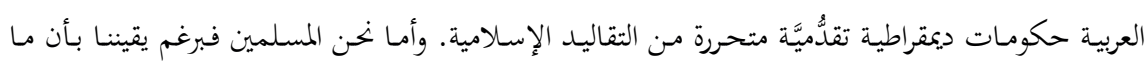

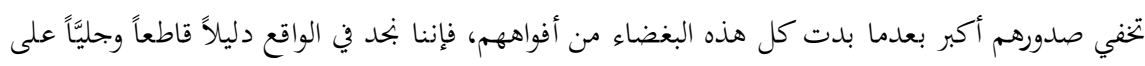

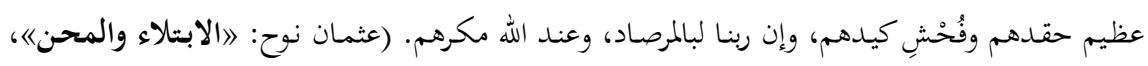




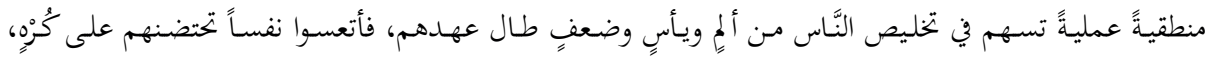

$$
\text { وأوهنوا جسداً يحملهم على مَضَضٍِ }
$$

إن طريق الخلاص أمام أبناء الأُمَّة الإسلامية واضحةٌ معالمه، تُنِيْرُهُ في النَّهار بوارق السيوف التي لا يطيقُ كَسَرَ عينَ

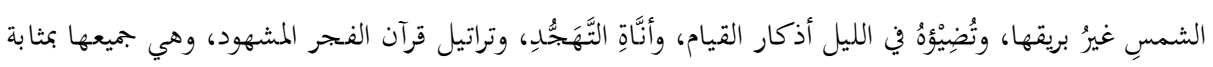

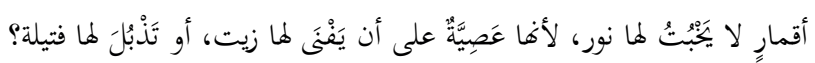
نعم؟! إن طريق النجاة أمام المسلمين يتيم، وسُبُلُ غيره ماضية بهم دون ريب نحو الجحيم؟

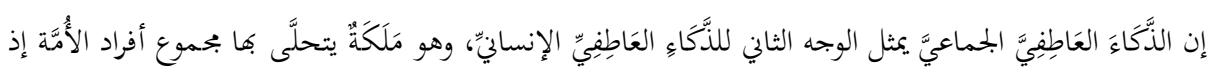

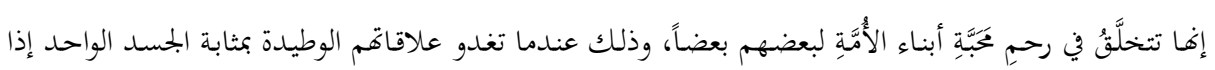
اشتكى منه عضو تداعى له سائر الجسد بالسَّهر والحمَّى، وهي تثمر عن أداء جماعي مبدع يستطيع المسلمون أو غيرهم من خلاله صناعة أبحاد الأُمَّة المنشودة، لأن يد الله على الجماعة، وبمثل هذا التعاضد الخَّلَّق استطاع الرعيل

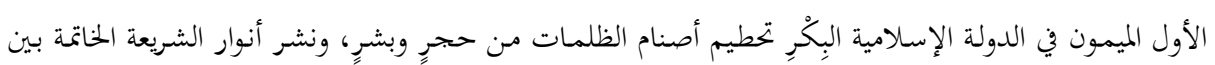
المشرقين. إن الذَّكَاءَ العَاطِفِيَّ قادرُ على ردم الهوَّة التي أمست عميقة فيما بين المسلمين مع بعضهم البعض من وَجْهِ؛ وهو يمكُِّ المسلمين من إعادة ترتيب سلم أولويات مشروعهم الإصلاحي مع الأمم الأخرى من وَجْهِ ثانٍ، إنه بوصلةٌ دقيقةٌ لا ثُحِيُّ العواطف في محافل العقل، بل بتعلها رقيبة على أدائه المنطقي، وهي مؤمنة بأهمية دور العقل في ميادين نشاطها في قطاعاته كافة. إن الذَّكَاءَ العَاطِفِيَّ في علم النَّفس التربويِّ الإسلاميِّ يُخْنَصَرُ في اجتهادك من أجل أن ترضي ربك، وتتعرَّفَ على طاقات نَفْسِك، وتتعامل مع النَّس في ضوء ضوابط شريعتك.

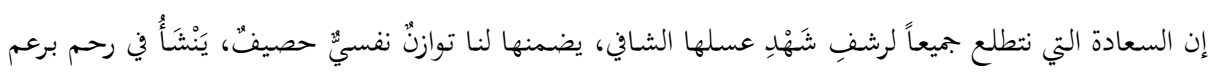
الإيمان، ويَتَخَلَّقُ في أكنافِ زهرٍ التقوى، ويُتْمِرُ عن خيرٍِ غفيرٍ تحت عناية ألطاف عين الله سبحانه وتعالى التي لا تأخذها سِنَةُ ولا نوم. 


\section{ثالثاً: نتائج البحث وتوصياته}

خلص الباحث إلى جملة من النتائج والتوصيات, ومن أهمها:

1- الذَّكَاءُ العَاطِفِيُّ هو علم معتبر ينبغي على الباحثين المتخصصين في علوم النفس والتربية الإسلامية معالجته وفق الرؤية الإسلامية الرشيدة.

2- وثَّقت الدراسة بنحاح مناهج التربية الإسلامية الشاملة والعميقة في تخريج أجيال من أبناء الأمة المسلمة الذين تحلو بأعلى درجات الذَّكَاءٍ العَاطِفِيٍ. 3- توصي الدراسة بأهمية إبحاز دراسات تحليلية تأصيلية نقدية تفنّد دعوى عجز الفكر التربوي الإسلامي عن محاكات ما تطالعنا به علوم العصر من فتوحات علمية (نفسية وتربوية) عبر تأكيد صلاحية الشريعة الإسلامية الخاتمة لبناء الإنسان الصالح الناجح في كل عصر ومكان. 


\section{رابعاً: مصادر البحث ومراجعه}

\section{القرآن الكريم.}

أحمد بن الحسين الخراساني أبو بكر البيهقي: شعب الإيمان، تحقيق الدكتور عبد العلي عبد الحميد حامد، مكتبة

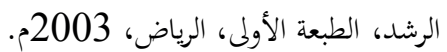

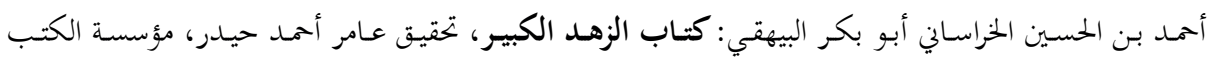

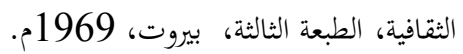
أحمد بن الخطيب البغدادي: الجـامع لأخحلاق الراوي وآداب السـامع، تحقيق محمود الطحان، مكتبة المعارف،

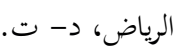
أحمد بن علي بن حجر العسقلاني: المطالب العالية بزوائد المسانيد الثمانية، تنسيق سعد بن ناصر بن عبد

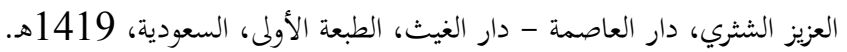
أحمد بن مروان الدينوري المالكي: المجالسة وجـواهر العلم،، تحقيق مشهور بن حسن آل سلمان، جمعية التربية الإسلامية، البحرين، 1419 هـ.

الحاكم محمد بن عبد الله النيسابوري: المستدرك على الصحيحين، تحقيق مصطفى عبد القادر عطا، دار الكتب العلمية، الطبعة الأولى، بيروت، 1990 190 مبد. دانييل جولمان: الذكاء العاطفي، ترجمة ليلى الجبالي، سلسلة عالم العرفة، العدد 262، 2000م.

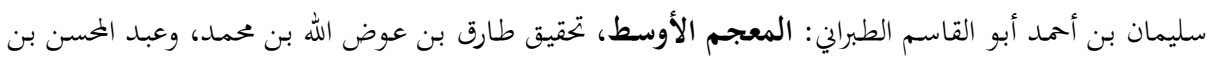

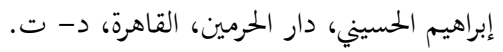
شمس الدين أحمد ابن خلِّكان البرمكي الإربلي: وفيـات الأعيان وأنباء أبناء الزمان، تحقيق إحسان عباس، دار

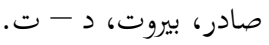
شيرويه بن شهردار أبو شجاع الديلميٌّ الهمذاني: الفردوس بمأثور الخطاب، تحقيق السعيد بن بسيوني زغلول، دار

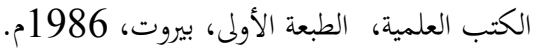
عبده كوشك: صفحات مشرق من تاريخ أعلام الأمَّة، دار الفيحاء، الطبعة الأولى، دمشق، 2009م. عثمان نوح: الابتلاء والمحن، دار الإيمان، الاسكندرية، د - ت. ت. علي بن أبي الكرم عز الدين ابن الأثير: أسد الغابة في معرفة الصحابة، تحقيق علي محمد معوض، وعادل أحمد عبد الموجود، دار الكتب العلمية، الطبعة الأولى، 1994م. 
علي بـن الحسـن المعـروف بـابن عساكر : تـاريخ دمشـق، تحقيق عمـرو بـن غرامـة العمـروي، دار الفكر، دمشـق، 1995 م.

مُحَمَّد بن إسماعيل البخاري: صحيح البخاري، تحقيق مصطفى البغا، دار العلوم الإنسانية، الطبعة الثانية، دمشق،

مُحَمَّد بن جرير الطبري: جامع البيان في تأويل القرآن، تحقيق أحمد مُحََّّد شاكر، مؤسسة الرسالة، الطبعة الأولى، بيروت، 2000م. محمد فاروق النبهان: خواطر مضيئة من وحي الأيام، دار التراث، الطبعة الأولى، حلب, 2007م.

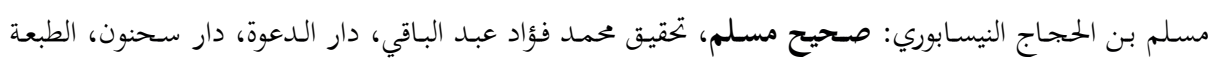

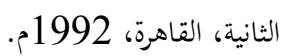
مصطفى أحمد الزرقا: عظمة محمد خاتم رسل الله مجمع عظمات البشر, دار القلم, دمشق, 2008م. مصطفى السباعي: دروس من الحياة، دار الوراق- ودار النيربين، الطبعة الأولى، دمشق، 2002م.

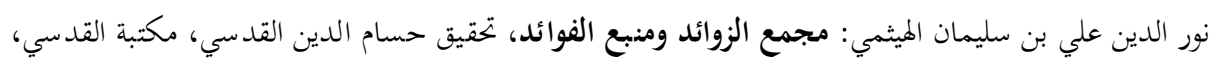
القاهرة، 1994م.

ياسر تيسير العيتي: الذكاء العاطفي، نظرة جديدة في العلاقة بين الذكاء والعاطفة،دار الفكر، دمشق، الطبعة

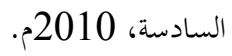
ياسر تيسير العيتي: ما فوق الذكاء العاطفي حلاوة الإيمان،دار الفكر، دمشق، 2009م. 
Al kuran al karim

Shwab al imaan- al baihaki, 2003.

Kitab al zwhd al kabir-- al baihaki, 1969.

Al jamia liakl al rawi wa aadaab al samia - al bagdadi

Al matalib al alia bizawaad al masanid al samania- al askalani, 1419.

Al majalia wa jawahir al ilim- al maliki, 1419.

Al mwstadrak ala al sahihin - al nisabori, 1990.

Alzakaa al aatyfy - jolman, 2000.

Al mwajam al awsat - al tabari

Wafiat al aeian wa anbaa abnaa al zaman - eben kalakan

Al firdaws fimaswr al kitaab- al hamazani, 1986.

Safaht moshrika - koshak, 2009.

Al ibtilaa wa al mihaan- noh

Asd al gabaa fi marifate al sahaba - eben al asir, 1994.

Tarih demashk - eben asaker, 1995.

Sahih al bokari - al bokari, 1993.

Jamia al bayan fi tawil al kuraan - al tabari, 2000.

Kawater mdiaa min wahi al aiaam- al nabhan, 2007.

Sahih mwslim - al naisabori, 1992.

Azamat muhamad katem al rwsul - al zarke, 2008.

Dwrws min al haia - al sibai, 2002.

Majmaa al zawaid wa manbaa al fawaaid - al haiami, 1994.

Alzakaa al aatyfy - al aiti, 2010.

Alzakaa al aatyfy halawat al imaan - al aiti, 2009. 
